\title{
Re-Recognizing the Cellular Origin of the Primary Epithelial Tumors of the Liver
}

\author{
Jiliang Feng' \\ Ruidong Zhu (D) ${ }^{2}$ \\ Yu Yin (iD) ${ }^{3}$ \\ Shanshan Wang' \\ Lei Zhou ${ }^{4}$ \\ Fudong Lv' \\ Dawei Zhao ${ }^{5}$ \\ 'Clinical-Pathology Center, Beijing You-An \\ Hospital, Capital Medical University, Beijing, \\ I00069, People's Republic of China; \\ ${ }^{2}$ General Surgical Center, Beijing You-An \\ Hospital, Capital Medical University, Beijing, \\ 100069, People's Republic of China; \\ ${ }^{3}$ Department of Pathology, Anhui Medical \\ University, Hefei, 230032, People's Republic \\ of China; ${ }^{4}$ Department of Pathology, First \\ Affiliated Hospital of Bengbu Medical \\ College/Bengbu Medical College, Bengbu, \\ 233004, People's Republic of China; \\ ${ }^{5}$ Department of Medical Imaging, Capital \\ Medical University, Beijing, 100069, \\ People's Republic of China
}

\begin{abstract}
The primary epithelial tumors of the liver (PETL) are composed of a series of heterogeneous tumors. Although the classification of PETLs has been updated several times by the World Health Organization, the cellular origins of some tumors in this family remain to be precisely depicted. In addition, certain tumors in different categories have similar histology, molecular phenotypes and biological characteristics, suggesting that they may have the same cellular origin. In this work, a narrative review method was adopted to review the relevant papers. By comparing the expression profiles of biomarkers of liver epithelium at different lineages and stages of differentiation, the cells-of-origin of some major members of the PETL family were reassessed. We propose that 1) hepatic adenomas, hepatocellular carcinomas (HCCs) and pure fetal hepatoblastomas (HBs) share the same spectrum in their cellular origin including the hepatocytic-committed progenitors (HCP) and their differentiated descendants. 2) Bile duct adenomas, peribiliary cysts and intrahepatic cholangiocellular carcinomas (ICCs) can share the same spectrum in their cellular origin including the cholangiocytic-committed progenitors (CCP) and their differentiated descendants. 3) The cells-of-origin of embryonal HBs include liver stem cells (LSCs), hepatoblasts, and transitional cells between them. Embryonal HB with small cell element, small cell undifferentiated HB and small cell neuroendocrine carcinoma of the liver can have the same or similar cellsof-origin from LSC. Embryonal HB lacking the small cell component of the LSC phenotype and presenting both hepatocytic and bile duct/ductule components may originate from actual hepatoblasts/hepatic progenitor cells (HPCs) as the combined HCC-ICC does. 4) Teratoid hepatoblastoma and mixed epithelial/mesenchymal HBs can be derived from the LSCs or even less committed extrahepatic pluripotent stem cell. 5) Many members of the PETLs family, including those derived from LSCs, hepatoblasts/HPCs, early HCPs and CCPs, have neuroendocrine potentiality. Except for those primary hepatic neuroendocrine tumor (PHNET) exhibit hepatocytic and/or cholangiocytic phenotypes, other PHNETs subtype may be derived from the descendants of LSC that differentiate towards the upper digestive tract, pancreas or other lineages.
\end{abstract}

Keywords: HCC, tumor-initiating cell, hepatic progenitor, neuroendocrine tumors, hepatoblastoma

\section{Introduction}

Most tumors are unicellular in origin. That is, a normal cell acquires the advantage of clonal proliferation and becomes a tumor-initiating cell (TIC). This normal cell is defined as the normal origin cell (NOC) of TIC. All the parenchymal cells that constitute the tumor mass are the offspring of TIC. The formation of TIC was initially understood to be the result of dedifferentiation of mature cells. Nowadays, it has been realized that as long as adequate mutations are accumulated,
Clinical-Pathology Center, Beijing You-An Hospital, Capital Medical University, No. 8, Xitoutiao, Youanmenwai Street, FengTai District, Beijing, 100069, People's Republic of China

Tel +86-10-83997342

$\mathrm{Fax}+86-10-83997343$

Email jiliangfeng@ccmu.edu.cn 
proliferating cell at any differentiation stage can become a TIC. Moreover, evidence of multi-lineage origin has been piled up in tumors of multiple systems. ${ }^{1,2}$

There is a regularity that tumors derived from lessdifferentiated NOCs are usually more aggressive, which was first observed in lymphohematopoietic malignancies. For example, patients with lymphoblastoma and lymphoblastic leukemia usually have worse clinical outcomes than patients with non-lymphoblastic leukemia and lymphoma. The biological behavior of lymphoma/leukemia derived from a mature cell type, such as B-cell chronic lymphocytic leukemia/small lymphocytic lymphoma, mantle cell lymphoma and follicular lymphoma are relatively inert. Later, this phenomenon was found in somatic tumors. ${ }^{1,3}$ Although genetic and epigenetic aberrant has been considered to be the root causes of the malignant phenotype of tumors, the influence of the cellular origin on the biological behavior of tumors suggests that cellular origin can be a variable independent of genetic- or epigenetic-abnormalities that contribute to the aggressive biology of TICs. Therefore, tracing the cellular origin of tumors more precisely will enable us to establish a classification closer to the clinic.

The primary epithelial tumors of the liver (PETL) are composed of a series of heterogeneous tumors, including hepatoblastoma (HB), hepatocellular carcinoma (HCC), intrahepatic cholangiocellular carcinoma (ICC), combined HCC-ICC, neuroendocrine tumor, hepatic adenoma, bile duct adenoma, etc. ${ }^{4}$ Although the classification of PETLs has been updated several times by the World Health Organization (WHO), the cellular origins of some tumors or their subtypes of this family remain ambiguous. In addition, some tumor entities in different categories have similar morphological and molecular characteristics and clinical manifestation suggesting that they may be the same tumor entity. In this work, some major members of PETLs in pediatric and adult were included in the same system for analysis. By referring to the histology and differentiation-related biomarkers of the normal liver parenchyma cells, cellular origins of these tumors were reassessed, which may enable us to move towards a precise classification and individualized treatment scheme in future.

\section{Methods}

There are two standard types of literature reviews: systematic reviews and narrative reviews. Unlike systematic reviews, which benefit from guidelines such as PRISMA
(Preferred Reporting Items for Systematic Reviews and Meta-Analyses), narrative reviews have no restrictive rules and acknowledged guidelines. However, a narrative review is irreplaceable to track the development of a scientific principle or clinical concept. As the focus of this paper is to discuss the cellular origin of almost all primary hepatic epithelial tumors and propose a conceptual framework for the future classification of PETL, a narrative review method was adopted to review the relevant papers. We also combined the consensus of pathologists with 20-30 years of diagnostic experience from three different hospitals to form this manuscript. Although subjectivity in literature selection and clinical experience may potentially leads to biases, we still believe it needed to present our conceptions and arouse researchers' interest to think and discuss the related issues. This review covers the cellular origins of almost all major members of the PETL family. By comparing the expression profiles of biomarkers of liver epithelium at different lineages and stages of differentiation, the cells-of-origin of the tumors or their subtypes was reassessed. All sections used for case presentation in this paper were re-stained with hematoxylin and eosin, D-PAS, and immunohistochemical staining. Antibodies used are listed in Table 1. All slides were assessed independently and blindly by the pathologists involved in this work. A consensus was reached by careful discussion in case of any disagreement among the evaluators.

\section{Main}

\section{Lineage Relationship and Molecular Phenotypes of Parenchymal Cells in Developmental Liver}

Our knowledge of somatic cell types comes from embryonic development and organogenesis. During liver development, a complex program of gene expression, which is determined by epigenetic modulation changes dynamically. Parallel to this, all products of gene expression, such as cytokeratins, fetal proteins and adhesion molecules, etc must be coordinated. Although the understanding and definition of hepatic parenchymal cells in early research has limitations and even contradictions, the combination of the expression pattern of biomarkers and cell differentiation capabilities enables us to identify different types of parenchymal cells in liver today. 
Table I Monoclonal Antibodies Used in This Study

\begin{tabular}{|c|c|c|c|c|c|}
\hline Antibody & Dilution & Clone & Company & Place of Production & Catalog No. \\
\hline Mouse anti-human CKI9 & $\mathrm{I}: 100$ & BAI7 & Zeta Corp. & Sierra Madre, CA, USA & $\mathrm{Z} 2134$ \\
\hline Mouse anti-human GPC3 & $\mathrm{I}: 200$ & $1 G \mid 2$ & Zeta Corp. & Sierra Madre, CA, USA & Z2103 \\
\hline Mouse anti-human CK7 & Ready-to-use & UMABI6I & ZSGB-BIO & Beijing, China & ZM-007I \\
\hline Mouse anti-human EpCAM & Ready-to-use & UMABI3I & ZSGB-BIO & Beijing, China & ZM-0359 \\
\hline Mouse anti-human NCAM & $\mathrm{I}: 200$ & I23C3.D5 & Zeta Corp. & Sierra Madre, CA, USA & Z2038 \\
\hline Rabbit anti-human AFP & Ready-to-use & EP209 & ZSGB-BIO & Beijing, China & ZA-06I2 \\
\hline Mouse anti-human $\mathrm{CK} 8 / \mathrm{I} 8$ & Ready-to-use & B22.I and 23.I & ZSGB-BIO & Beijing, China & ZM-03I5 \\
\hline Mouse anti-human HepPar-I & Ready-To-Use & OCHIE5 & ZSGB-BIO & Beijing, China & ZM-0I3I \\
\hline Mouse anti-human Glutamine synthetase & Ready-to-use & D-6 & ZSGB-BIO & Beijing, China & ZM-0I25 \\
\hline Mouse anti-human Chromogranin & Ready-to-use & LK2HIO & ZSGB-BIO & Beijing, China & ZM-0076 \\
\hline Rabbit anti-human Synaptophysin & Ready-to-use & EPI58 & ZSGB-BIO & Beijing, China & ZA-0506 \\
\hline Mouse anti-human CAI9-9 & Ready-to-use & $C 241: 5: 1: 4$ & ZSGB-BIO & Beijing, China & ZM-002I \\
\hline Mouse anti-human $\beta$-catenin & Ready-to-use & UMABI5 & ZSGB-BIO & Beijing, China & ZM-0442 \\
\hline Mouse anti-human LFABP & $\mathrm{I}: 100$ & L2BIO & OriGene Tech. & Rockville, MA, USA & AM26273PU-N \\
\hline Rabbit anti-human CDI33 & $\mathrm{I}: 100$ & EMК08 & OriGene Tech. & Rockville, MA, USA & TA350943 \\
\hline
\end{tabular}

In Table 2, the molecular phenotypes of different parenchymal cells in developmental liver were summarized. In the third to fourth week of gestation, the liver bud arises from the foregut. Liver bud cells are multipotential with CK8 +/CK18+/CK7-/CK19-/AFP- expression profile. They can be the most primitive stem cell type of the liver (LSCs). ${ }^{5-8}$ With further differentiation, a stem cell population with CK8 +/CK18+/CK7+/CK19+/AFP- expression emerge. These cells retain the multi-potency and are therefore still regarded as LSCs. ${ }^{9-11}$ Hepatoblasts are derived from LSCs and are positive for CK8, CK18, CK7 and CK19. However, hepatoblasts can express fetal protein AFP and GPC3, which distinguishes them from LSCs. ${ }^{8-10,12,13}$ In human fetal liver, both LSCs and hepatoblasts can express EpCAM. ${ }^{8,9,14-16}$ Most studies reported that neuroendocrine markers NCAM and chromogranin were positive for hepatoblasts and LSCs, but their expressions were not detected in certain subsets of hepatoblasts and LSCs. ${ }^{6,9,10,14}$

Hepatoblasts have bi-potential to differentiate into hepatocytic or cholangiocytic lineage cells. When hepatoblasts are committed to hepatocytic lineage, early hepatic cord cells (early HCP) can still express CK19, CK7, EpCAM, AFP, GPC3, NCAM and chromogranin. With further differentiation, their expression is gradually decreased, till approaching to maturity, disappeared..$^{7-9,12,13,17-20}$ Alternatively, when hepatoblasts are committed to cholangiocytic lineage, the early CCPs can still express NCAM and EpCAM. With further differentiation, their expression is lost. ${ }^{6,8,9,12,16}$ CK7, CK19, CK8 and CK18 are expressed in all epithelia of the cholangiocytic lineage, while AFP and GPC 3 are not. ${ }^{17}$
Studies on the fetal liver of different gestational ages have found that the development of the intrahepatic bile duct begins with the ductal plate (DP), a double-layered cylindrical structure located in the interface between hepatoblasts and portal mesenchyme. The DP undergoes remodeling and remodeled DP stages, and finally forms mature intrahepatic bile duct. ${ }^{6}$ The development of the intrahepatic bile duct can reflect the differentiation and maturation lineage of the cholangiocytic epithelia. Evidence from different literature suggests that cells that make up DP have a molecular phenotype and bipotential similar to that of hepatoblasts. ${ }^{6,22}$ DP cells express CK8, CK18, CK7, CK19, EpCAM and AFP. ${ }^{6,7,9,12,16,18}$ They also express neuroendocrine markers, chromogranin, synaptophysin and NCAM. EpCAM, chromogranin, synaptophysin and NCAM are expressed in the remodeling DP cells and then disappear with further differentiation. ${ }^{6,9,15}$ Still, multipotential stem cell in DP was uncovered suggesting that DP is also niche for LSCs. ${ }^{6,21,22}$ Terada identified a subset of more "primitive hepatoblast" that were positive for CK8 and CK18, but negative for CK7, CK19 and neuroendocrine biomarkers, chromogranin, synaptophysin, CD56 and NSE. ${ }^{6}$ The molecular phenotype of these cells is consistent with that of LSC in fetal and adult liver described by other scholars. $5,7,8,14$

\section{Lineage Relationship and Molecular Phenotypes of Parenchymal Cells in Adult Liver}

In normal conditions, adult liver cells have very little proliferative activity. However, in the context of liver injury, both mature and stem cells can proliferate. In 


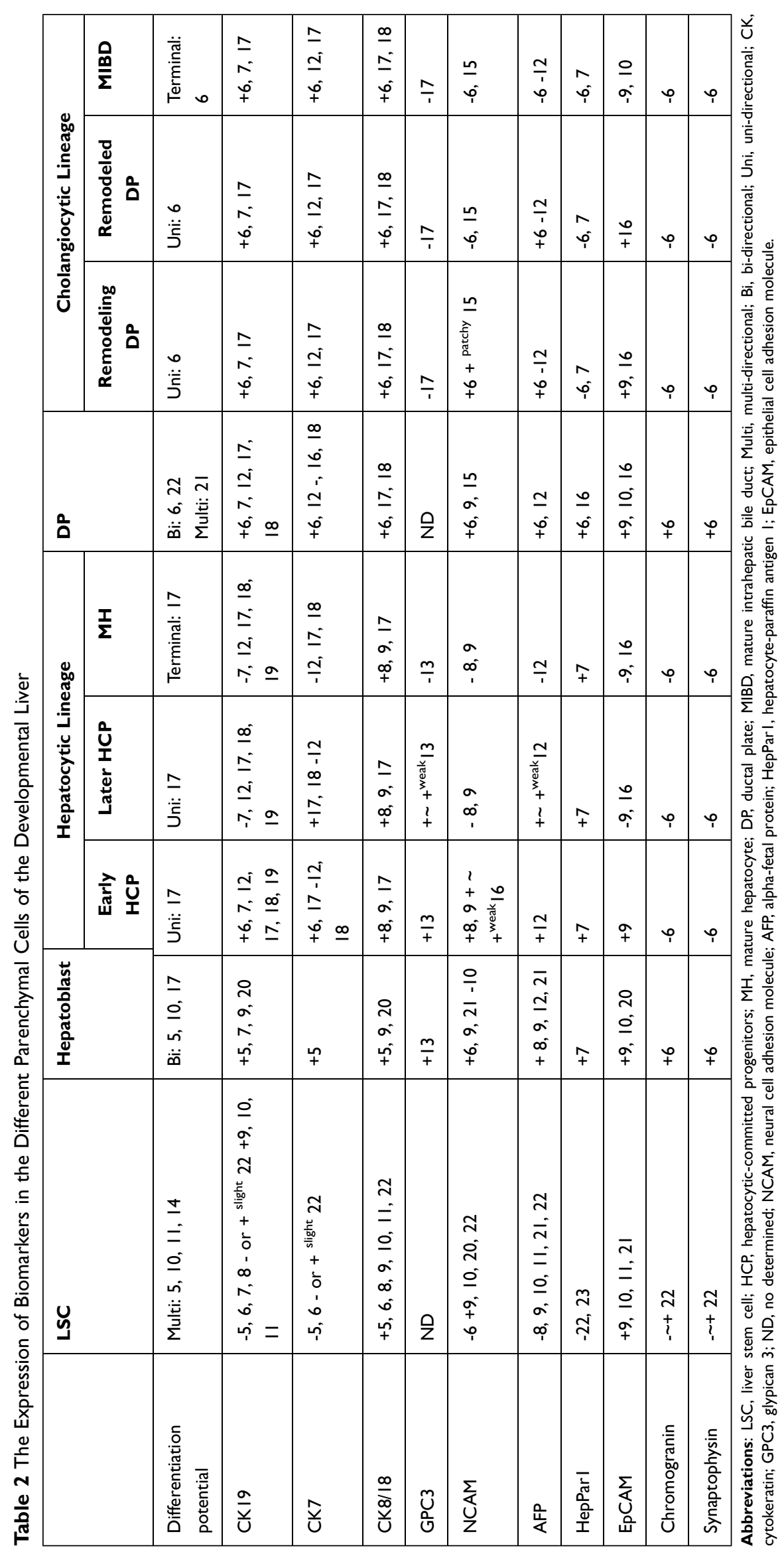


response to acute injury, liver is repaired primarily by mitosis of mature hepatocytes. In the case of extensive liver injury, hepatic progenitor cells (HPCs) are activated to compensate for cell loss. ${ }^{4,23}$ In Table 3, the molecular phenotypes of different parenchymal cells in adult liver were summarized. In adult liver, the canals of Hering are thought to be the niche of HPCs. HPCs have almost the same molecular phenotype and bipotential as hepatoblasts, suggesting that HPCs are the counterparts of hepatoblasts in adult liver. ${ }^{11,23-27}$

Being committed towards hepatocytic or cholangiocytic lineage, HPC will undergo transitional stages of differentiation before it matures. When differentiating towards the hepatocytic lineage, CK19, CK7, NACAM, GPC3, AFP, chromogranin and synaptophysin can be expressed in early HCPs, then reduced, and finally absent in mature hepatocytes. ${ }^{17,23-26}$ Alternatively, when differentiating towards the cholangiocytic lineage, the early CCPs are cuboidal and do not produce mucin. ${ }^{20}$ The early CCPs can express NCAM, EpCAM and CD44, but not tumorassociated mucin proteins. ${ }^{23,28,29}$ Later, they gradually lost the expression of the stem cell markers and start to express markers of mature cholangiocytes such as secretin receptor. ${ }^{30,31}$ Mature cholangiocytes are cylindrical and constitute the extrahepatic and intrahepatic large bile ducts.

In adult liver, HPCs have long been considered as the only stem cell type. Past decade, LSCs in the peribiliary glands of the neonatal and adult liver were identified. The molecular phenotype and differentiation potential of these LSCs are almost the same as those of LSCs in embryonic development. ${ }^{10,14,20-22,28}$ Placed in appropriate media, LSCs can differentiate into intestinal and pancreatic epithelial cells and fat, bone, cartilage, and endothelial cells. ${ }^{11}$

In short, the lineage relationships of parenchymal cells and the molecular phenotypes of the corresponding cells between developing and adult livers are almost identical. Although there is overlapping biomarker expression between adjacent cell types in a differentiation lineage, different parenchymal cell types are often distinguishable by morphological and subtly different immunohistochemical expression patterns.

\section{In General, Tumor-Initiating Cells Can Be Mapped to Different Differentiation Hierarchies of Normal Stem Cells}

Tracing the histological or cellular origin of tumors has always been the core content of tumor pathology. In practice, pathologists usually determine the cellular origin of various tumors by comparing the expression patterns of tumor cell markers with those of their normal counterpart cells. Obviously, this method is based on a hypothesis, that is, after transformation, tumor-initiating cells will be mapped to different differentiation hierarchies of normal stem cells. It is just based on this hypothesis that the classification standards and guidelines for tumors of various systems have been developed and are widely used in clinical practice today. In spite of this, many studies suggested that de-differentiation or trans-differentiation can exist during the liver injury and regeneration process, thereby promoting the development of tumors.

In liver, the de-differentiation hypothesis suggests that mature hepatocytes or cholangiocytes can becomes less differentiated stem cells, and trans-differentiation refers to hepatocyte and cholangiocyte could change into each other. Liver cell injury and regeneration induced by carbon tetrachloride (CCl4), dimethylnitrosamine (DMN), hepatectomy or partial devascularization are the main experimental models, by which stem cells, mostly, HPCs were enriched. Huch et al reported that isolated EpCAM+ bile duct cells from the human liver can be induced to transdifferentiate into hepatocytes. ${ }^{32}$ Nishikawa reported that HNF-4 $\alpha+/$ CK8+/CK19- hepatocytes can transdifferentiate into CK19+ bile duct-like cells. ${ }^{33}$ Doffou reported that HNF- $4 \alpha+$ hepatocyte can transdifferentiate to biliary epithelial cells in vitro. ${ }^{34}$ In recent years, studies have found that in addition to biliary epithelial cells, EpCAM + and CK19 can also be expressed in HPC. In addition, Hnf- $4 \alpha$ can be expressed not only in mature hepatocytes but also in HPC. ${ }^{35}$ These evidence suggests that the previous studies on transdifferentiation between hepatocytes and cholangiocytes can have systemic flaws. Font-Burgada et al described periportal hepatocytes with Sox9+ expression can transdifferentiate into ductal cells after DDC dietinduced liver injury. ${ }^{36}$ Today, we know that SOX9 is a pan-stem cell marker. In the hepatobiliary system, SOX9 can be expressed in HPCs, ductal plate cells and small but not large bile ducts after birth. ${ }^{37}$

Tarlow BD reported that isolated fumarylacetoacetate hydrolase (FAH) positive hepatocytes can be dedifferentiated into bipotential adult liver progenitors with SOX9 expression. ${ }^{38}$ Although FAH has long been regarded as the biomarker of mature hepatocytes, recent literatures revealed that FAH can be expressed in human fetal liver, ${ }^{39}$ induced pluripotent stem cells (iPSC), early and late iPSC-hepatocyte-like cells, ${ }^{40}$ In fetal and mature liver, 


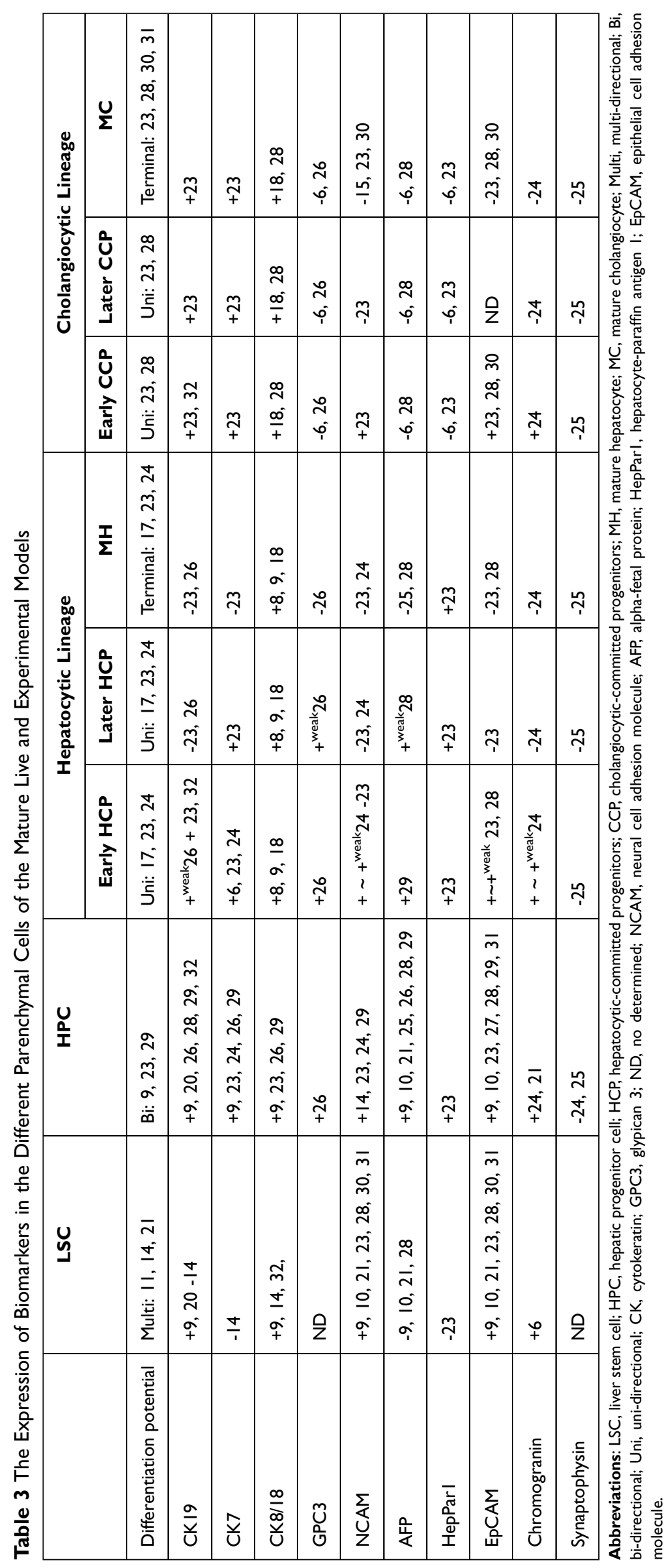


similar levels of FAH expression was observed. ${ }^{41}$ Lin et al reported that subset of $\mathrm{Lgr} 5+/ \mathrm{FAH}^{\mathrm{LOW}}$ liver cells possess bi-potential. ${ }^{42}$ These evidences imply that the FAH ${ }^{+}$ mature hepatocytes previously isolated by Tarlow $\mathrm{BD}^{38}$ may be mixed with dual-potential HPCs. Sekiya reported, albumin+/CK19- hepatocytes residing in the portal areas can give rise to the majority of the biliary lineage cells that form primitive ductules in DDC-induced chronically injured liver. ${ }^{43}$ Today, we know that liver stem cells have albumin+/CK19- phenotype. $^{5-8,10,14,44}$ which led us to speculate that Sekiya S's experimental model may represent the differentiation of hepatic stem cells rather than dedifferentiation of hepatocytes.

In 2020, Chao et al reviewed the molecular mechanisms of putative dedifferentiation in the development of HCC. ${ }^{45}$ The authors summarized many signaling pathways, such as Wnt/ $\beta$-catenin, TGF- $\beta 1 / \mathrm{Smad} / \mathrm{Snail} 1$, PI3K/AKT and Hedgehog of normal stem cells were activated in $\mathrm{HCC}$, thus inferring that dedifferentiation may be involved in the development of tumorigenesis. Mutations can indeed alter signaling pathways and give tumorinitiating cells a stemness, but it cannot be ruled out that HCC with a stem cell phenotype can directly inherit the epigenetic status of the above-mentioned signaling pathways from the normal corresponding initial stem cells. In addition, although somatic cells can be reprogrammed into pluripotent ES-like cells by ectopic expression of transcription factors such as Oct4, Sox2, Klf4, and C-MyC (OSKM $),{ }^{46}$ whether "dedifferentiation" can promote individual tumorigenesis without any additional manipulation needs to be supported by reliable evidence.

As long as adequate mutations are accumulated, proliferating cell at any differentiation stage can be transformed. Just based on this generally accepted principles, experienced pathologists can identify the histological or cytological origin of almost all tumors and their subtypes, although in a very small number of tumor cases significant phenotypic changes can be observed, making the exact origin difficult to trace. Therefore, de-differentiation or trans-differentiation mechanisms may contribute to tumorigenesis, but not dominant. In general, tumor-initiating cells can be mapped to different differentiation hierarchies of normal stem cells.

\section{Re-Evaluate the Cellular Origin of PETLs Hepatic Adenomas (HCAs)}

HCAs are benign clonal proliferations and also precancerous lesions of HCCs. Classical HCAs are characterized by appearance of monotonous sheets of well-differentiated hepatocytes, which closely resemble structure of the normal hepatic plates. Tumor cells of the classical HCAs express CK8, CK18 and HepPar-1, and normal levels of serum AFP. The morphological and molecular manifestations imply that the classical HCAs can originate from the mature hepatocytes. Still, some other studies showed that scattered CK19+ or CK7+ cells could be detected in nearly $50 \%$ of HCAs (Figure 1, magnification $\times 100$ ), and differentiation hierarchies of tumor cells $(\mathrm{CK} 7+/ \mathrm{CK} 19+$, CK 7 +/CK19- and CK7-/CK19- tumor cells) in these HCAs were observed. ${ }^{47}$ Some scholars have proposed that these CK19 or CK7 expression HCAs could be derived from HPC. ${ }^{47,48}$ Given the fairly uniform hepatic plate-like structure, these CK19 or CK7 expression HCAs should be considered as the origin of the unipotential cells, rather than HPCs.

The discovery of somatic mutations in HCAs has prompted a molecular-pathologic classification for this tumor by WHO [4]: 1) H-HCA, characterized by hepatic nuclear factor $1 \alpha(\mathrm{HNF} 1 \alpha)$ inactivation, is considered to be the least likely to undergo malignant transformation; 2) Inflammatory HCA (IHCA), characterized by the presence of inflammatory cell infiltration. A somatic activating mutation of gp130 led to the constitutive activation of the JAK/STAT pathway in IHCA was identified, which could explain the inflammatory phenotype. Ten percent of IHCAs have activation of $\beta$-catenin and are therefore nominated as $\beta$-IHCAs. Given the risk of malignant transformation, $\beta$-IHCA was merged with the next category in WHO classification system; 3$) \beta$-catenin-activated HCA $(\beta$-HCA) and $\beta$-IHCA: This subtype is characterized by CTNNB1 gene alterations and highly correlated with the malignant transformation. This classification system highlights the relationship between genetic alterations, but not cellular origins, and oncogenesis of HCAs.

In activated LSCs and HPCs, the Wnt $/ \beta$-catenin pathway is enhanced. ${ }^{49,50}$ Interestingly, HCAs with the expression of stem cell biomarker, such as CK7 can be observed in multiple HCA subtypes, mostly in $\beta$-IHCAs, ${ }^{51} \beta$-HCAs, and non-mutated, non-inflammatory HCAs, except for H-HCA. ${ }^{52,53}$ Although activation of Wnt/ $\beta$-catenin pathway through genetic mutations has been widely reported, the possibility of enhancement of this pathway in $\beta$-HCA or $\beta$-IHCA via epigenetic inheritance from the normal origin stem cells cannot be ruled out. This raises the question of whether HCAs derived from stem cells carries a higher risk of malignant potential. In-depth research on 
this issue may be of great significance for understanding the impact of epigenetics on tumor biology, tumor progression, and future clinical management of HCA.
In brief, HCA can originate from a variety of hepatocytic lineage cells of different differentiation, which does not include HPC.
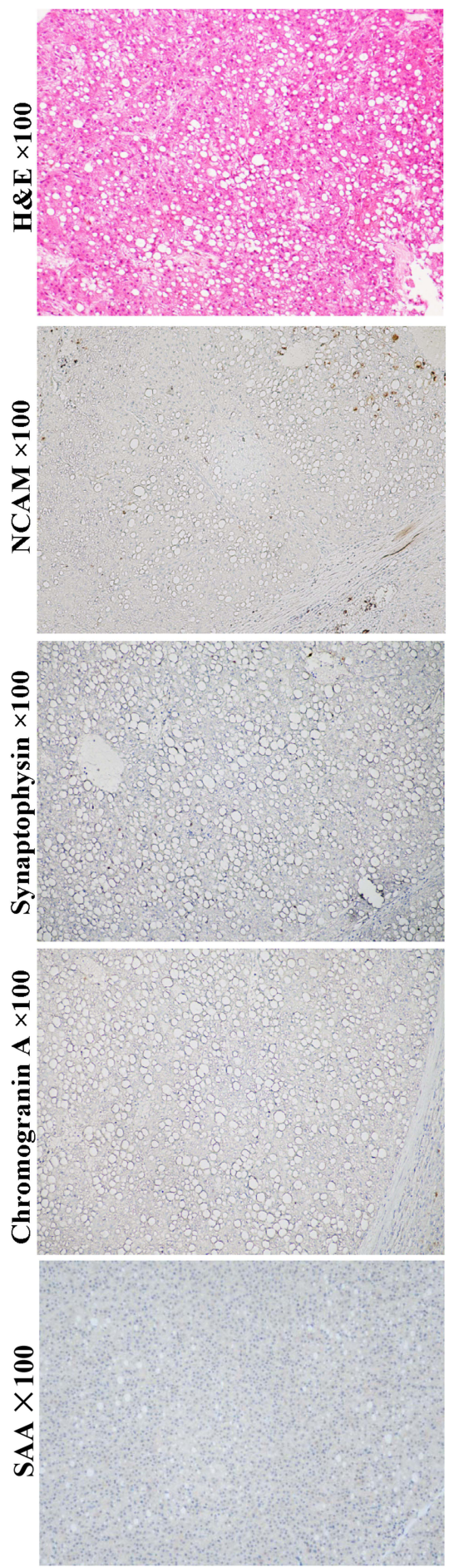
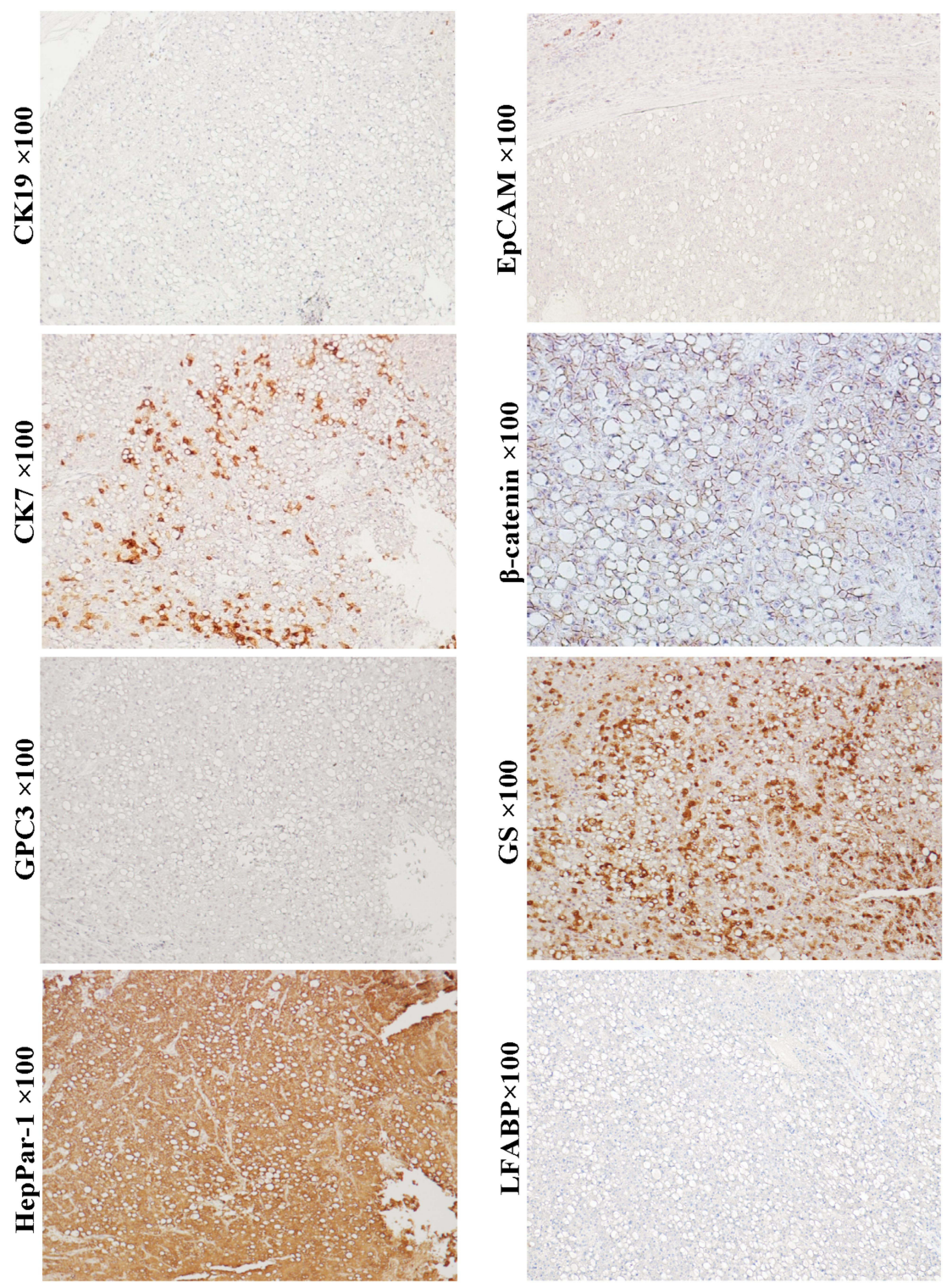

Figure I Example case of a hepatic adenoma (HCA) originated from the later HCP. A 65-year-old male patient with $4.5 \mathrm{~cm}$ sized tumor in the right lobe of the liver. His preoperative serum AFP was $4.8 \mathrm{ng} / \mathrm{mL}$. There was no tumor recurrence or extrahepatic metastasis in the 4-year follow-up after surgical resection. H\&E staining shows that the tumor cells are arranged in sheet-like structure lacking portal tracts. Steatotic tumor cells are present throughout the field of vision. Tumor cells do not express neuroendocrine marks NCAM, chromogranin and synaptophysin, as well as stem cell marker CKI9 and EpCAM. However, they can patchily express CK7. $\beta$-Catenin is expressed in the cell membrane and cytoplasm of tumor cells. The molecular profile of the HCA is consistent with that of the later HCP, suggesting these CK7+ cells might be at the top of the differentiation hierarchy of tumor cells. The tumor lacks the expression of LFABP and SAA, suggesting it is H-HCA. 


\section{HCCs}

Histological manifestations of HCC vary greatly. Several architectures, including thin or thick trabeculae, pseudoglands, acinus, and compact patterns have been described previously. Its cytological variants include pleomorphic cells, clear cell, chromophobe cell, spindle cell, etc. ${ }^{4}$

For a long time, HCCs have been considered to be derived from the mature hepatocytes due to genetic mutation. Later, the disclosure of HPCs in adult liver and the discovery of HCC with the expression of stem cell markers CK19, CK7, EpCAM, NCAM, GPC3 or AFP have led oncologists to speculate that HPCs could represent the origins of HCCs or certain subtypes of HCCs. ${ }^{54-56}$ Strictly speaking, co-expression of the stem cell markers EpCAM and NCAM, as well as the so-called cholangiocytic markers CK19 and CK7, cannot be used as absolute evidence to determine the HPC-origin for these tumors, because this molecular profile can be shared by normal HCPs, CCPs, and hepatoblasts/HPCs, indicating that morphological clues are crucial for judging the cellular origin of this tumor.

The presence of striped or antler-like structures with the expression of CK19 and CK7 can be the pitfall for HCC's HPC-origin hypothesis. These structures are usually present in the invasive front or periphery of tumor nests. In addition, in the entire tumor, only typical HCC morphology (eg, sheet, trabecular, acinar, or solid patterns) is present, and typical neoplastic tubule structure is absent. The evidence suggests that the HCCs expressing stem cell markers can originate from uni-potential cells, rather than HPCs.

It is worth noting that stem cell markers can only be detected in some, but not all, HCC cases. For example, CK7 or CK19 positive HCC cases account for approximately $40 \%$ and $10 \%$ of all HCC, respectively. ${ }^{54-56}$ Welldifferentiated HCCs usually appeared in acinar and/or thin trabecular patterns (1-3 cells-thick), which mimicked the normal hepatic plates. Well-differentiated HCC usually does not express stem cell markers, such as CK19, NCAM, EpCAM and chromogranin (Figure 2, magnification $\times$ 100). Their serum AFP levels are usually very low. ${ }^{54-56}$ Most studies showed that fetal protein GPC3 was negative or weak expressed in well-differentiated HCCs. Yamauchi et al observed that these well-differentiated HCCs with GPC3 positive staining usually in a pattern of prominent adjacent to canaliculi, as in the developing hepatic plate and regenerative nodule. More importantly, stem cell transcription factors, such as NANOG, OCT4, Sox2 and c-MYC are generally not expressed in well-differentiated HCCs. ${ }^{57}$ With the histological and molecular evidence, it supports that well-differentiated HCCs can originate from the mature or near-mature hepatocytes.

Scirrhous HCC (SHCC) (Figure 3, H\&E staining, magnification $\times 200$; Other staining, magnification $\times 100$ ) and fibrolamellar hepatocellular carcinoma (FLHCC) (Figure 4, magnification $\times 100$ ) are two rare variants of HCC that are morphologically similar due to their abundant fibrosis and cellular features. SHCC is characterized by small oval cells arranged in nests or trabeculae surrounded by diffuse fibrous stroma. ${ }^{58}$ Our previous study has showed that majority of SHCCs in our cohort showed CK19+/GPC3+ expression. ${ }^{2}$ Other literature also demonstrated that SHCCs can express other stem cell markers, such as NCAM, EpCAM and ATP-binding cassette transporter G2, in addition to CK19 and GPC $3{ }^{59}$ The histological and molecular characteristics suggest that SHCC may originate from early HCPs rather than HPCs. FLHCC is featured by polygonal cells with large nucleoli and copious eosinophilic cytoplasm and the presence of thick fibrous collagen bands. Previous studies have reported that $95 \%$ of FLHCC patients carry a specific DNAJB1-PRKACA fusion gene. Initially, FLHCC was found to stain strongly for CK7, CK8/18, HepPar-1, but negative for CK19, suggesting this tumor can originate from the later $\mathrm{HCPs}^{48}$ Subsequently, expression of CK19, EpCAM, and CD44 was observed in FLHCC, indicating that this tumor could have a wider spectrum of cells of origin, including early or later HCPs. Overexpression of TGF- $\beta$ may account for the lamellar pattern characteristics of FLHCC. Controversy exists regarding whether SHCC or FLHCC have a better prognosis than classical HCC. Several studies had described them as more indolent and associated with a better outcome, but subsequent studies reported that the prognosis of patients with SHCC or FLHCC was similar with that of patients with classical HCC.

In general, morphological classification and histological grading have certain value in judging the prognosis of HCC patients, but only highlight the good outcomes of patients with well-differentiated (thin trabecular) HCC., ${ }^{2,54,60}$ In recent years, the relationship between the cellular origin of HCCs and prognosis has been confirmed, and several classification systems have been proposed. ${ }^{54}$ We have subclassified HCCs into CK19+/GPC3+ (Figure 5, magnification $\times 100)$, CK19-/GPC3+ (Figure 6, magnification $\times 100)$, 

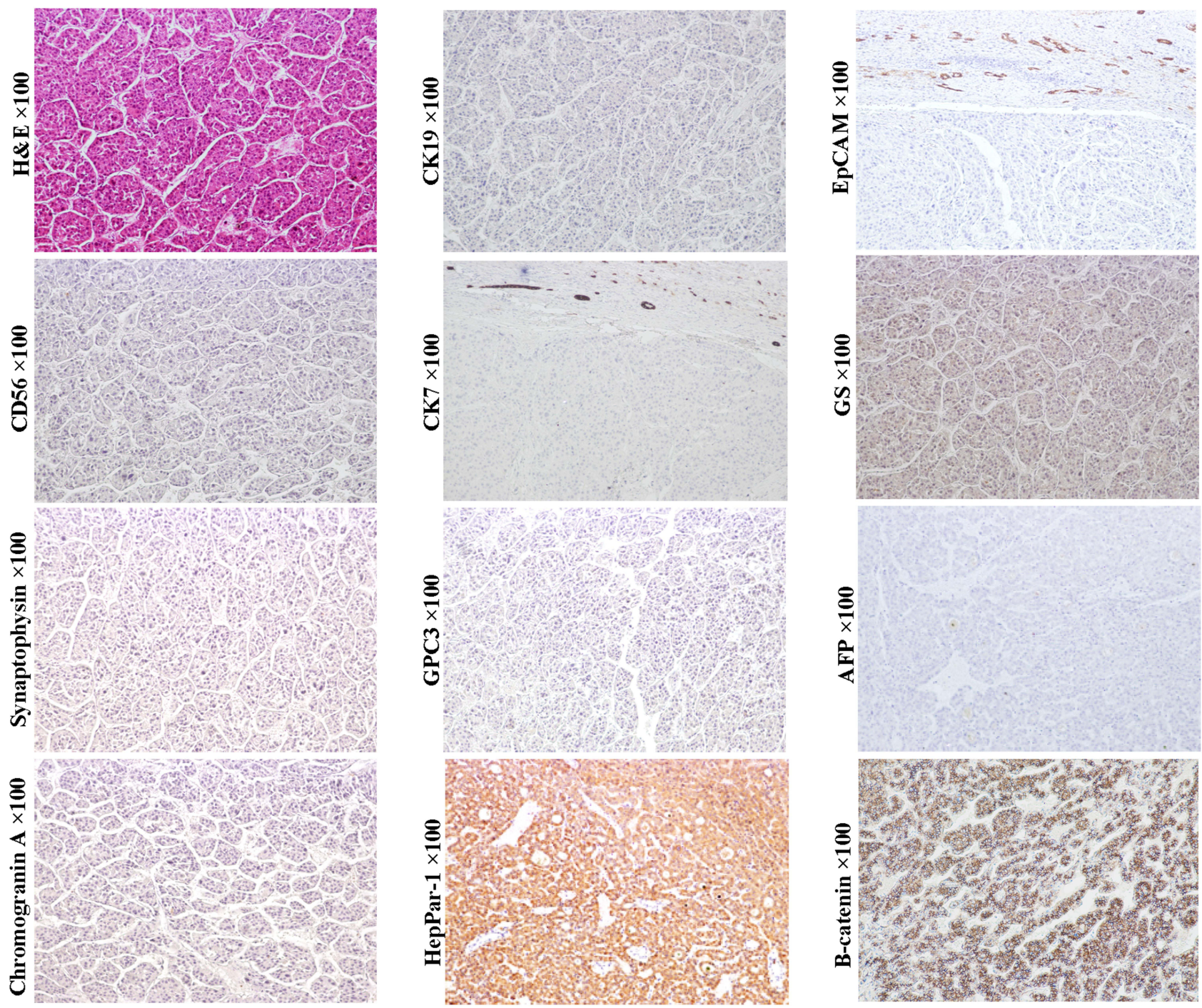

Figure 2 Example case of a well-differentiated HCC with CK 19-/GPC3- expression originated from the mature or near-mature hepatocyte. A 59-year-old male patient with $12 \mathrm{~cm}$ sized tumor in the right lobe of the liver. The patient has chronic hepatitis B infection. His preoperative serum AFP was $21.07 \mathrm{ng} / \mathrm{mL}$. Four months after radical hepatectomy, intrahepatic tumor recurrence was found, and lung metastasis was found I month later. Tumor cells are arranged in an antler-like or thin trabecular structures. They do not express stem cell markers EPCAM, CKI 9 and CK7, fetal protein GPC3 and AFP, and neuroendocrine marks NCAM, chromogranin and synaptophysin, but express HepParl. $\beta$-Catenin is expressed in the cell membrane and cytoplasm. The molecular profile is consistent with that of the normal mature or near-mature hepatocytes.

and CK19-/GPC3- (Figure 2, magnification $\times 100)$ phenotypes, which roughly corresponded to HCC subtype derived from the early, later HCPs and mature hepatocyte, respectively. Our results showed that from $\mathrm{CK} 19+/ \mathrm{GPC} 3+$ to CK19-/GPC3+, and finally CK19-/GPC3- HCC, the risk of microvascular invasion, regional lymph node involvement, intrahepatic and distant metastases were successively decreased. ${ }^{61}$ With the aid of this CK19/GPC3 classification system, our subsequent researches showed effective recurrence risk stratification of $\mathrm{HCC}$ patients after liver transplantation $^{58}$ and surgical resection. ${ }^{62}$ This work supports that HCC classification based on cellular origins is of great significance in optimizing treatment strategies.

Taken together, we provide here evidence that HCCs are heterogeneous tumors that can originate from a variety of parenchymal cells of the hepatocytic lineage, but not HPCs. Although many driver mutations related to the development of HCC have been identified, it is unclear whether these mutations have a preferential distribution in HCC subtypes of different origin. A comprehensive study 

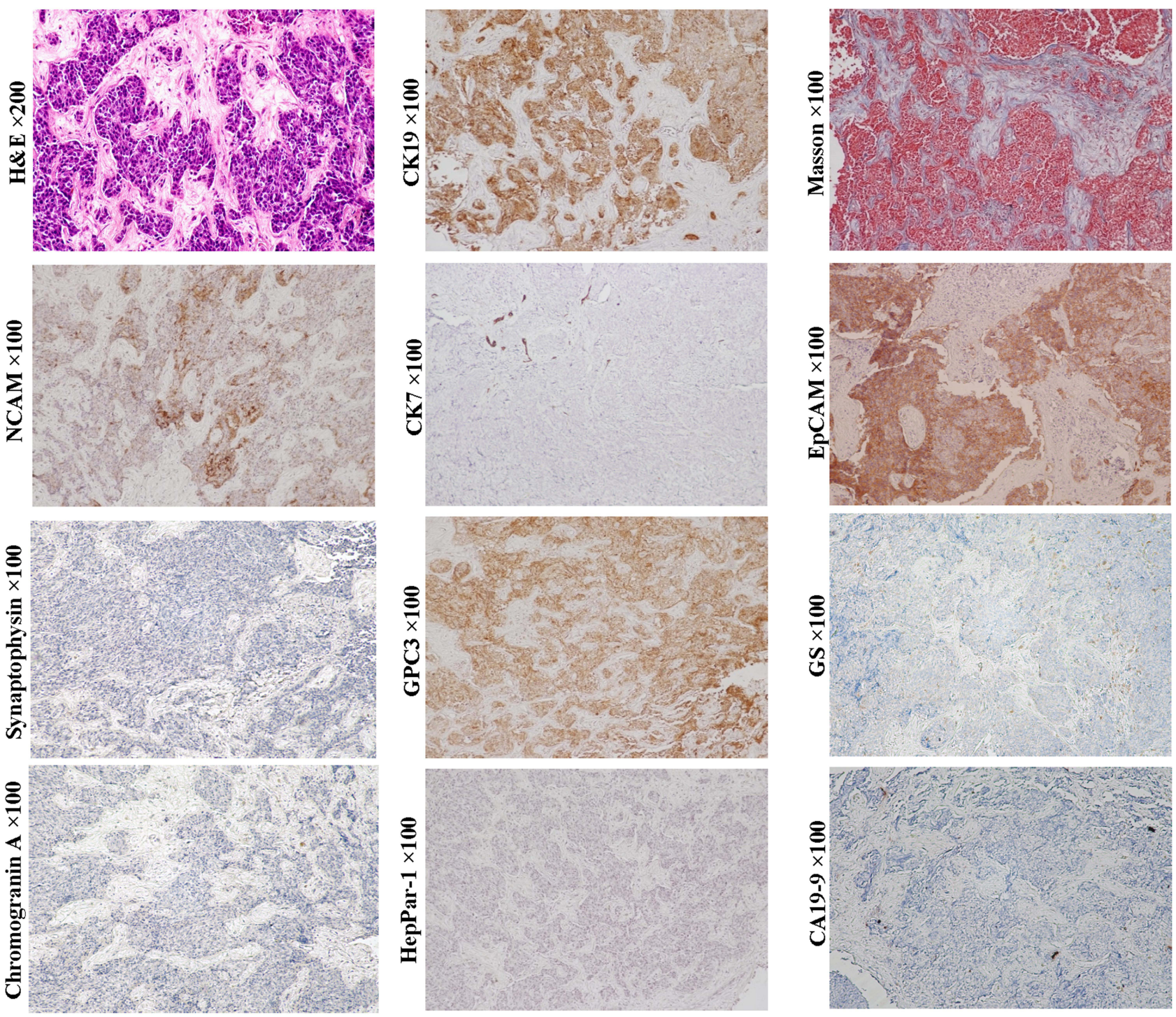

Figure 3 Example case of a scirrhous HCC originated from the early HCP. 66-year-old female patient with $5.0 \mathrm{~cm}$ sized tumor in the right lobe of the liver. Her preoperative serum AFP was $4.92 \mathrm{ng} / \mathrm{mL}$. Six months after radical hepatectomy, intrahepatic tumor recurrence was found. H\&E and Masson staining show that tumor cell nests are separated by fibrous cords of varying thickness. Tumor cells express stem cell markers EpCAM, CKI9 and GPC3, but not biomarker of the cholangiocarcinoma CAI9-9. Although the expression of chromogranin and synaptophysin were not detected, the expression of NCAM suggested that this tumor might have neuroendocrine potential. The molecular profile of this case is generally consistent with that of the early HCPs.

of HCCs that integrates genetic aberrant and cellular origin may help accurately depict the essential characteristics of this tumor in future.

\section{Combined HCC-ICCs}

By definition, a typical combined HCC-ICC is composed of three components. The cells of the first component have stem cell characteristics, also referred to as "transitional area cells." These cells are usually arranged in cord, ribbons or nest patterns and express stem cell markers NCAM, EpCAM, OV-6 or chromogranin, in addition to $\mathrm{CK} 8 / 18, \mathrm{CK} 7, \mathrm{CK} 19$, GPC3, AFP, GS, and
HepPar-1, which is consistent with that of HPCs and hepatoblasts. ${ }^{63,64}$ The other two components, including those with typical HCC and ICC characteristics, are indispensable. Although the transitional area cells can be observed in quite a few studies, in some cases, they can be poorly defined (Figure 7, magnification $\times 100$ ). The initial theory regarding the combined HCC-ICC was that it was a collision tumor. Given the bidirectional phenotype, the tumor is more likely to be an actual malignant counterpart of HPC in adults. Sometimes, fairly homogeneous undifferentiated small cells can be observed in the transitional area of some HCC-ICC 

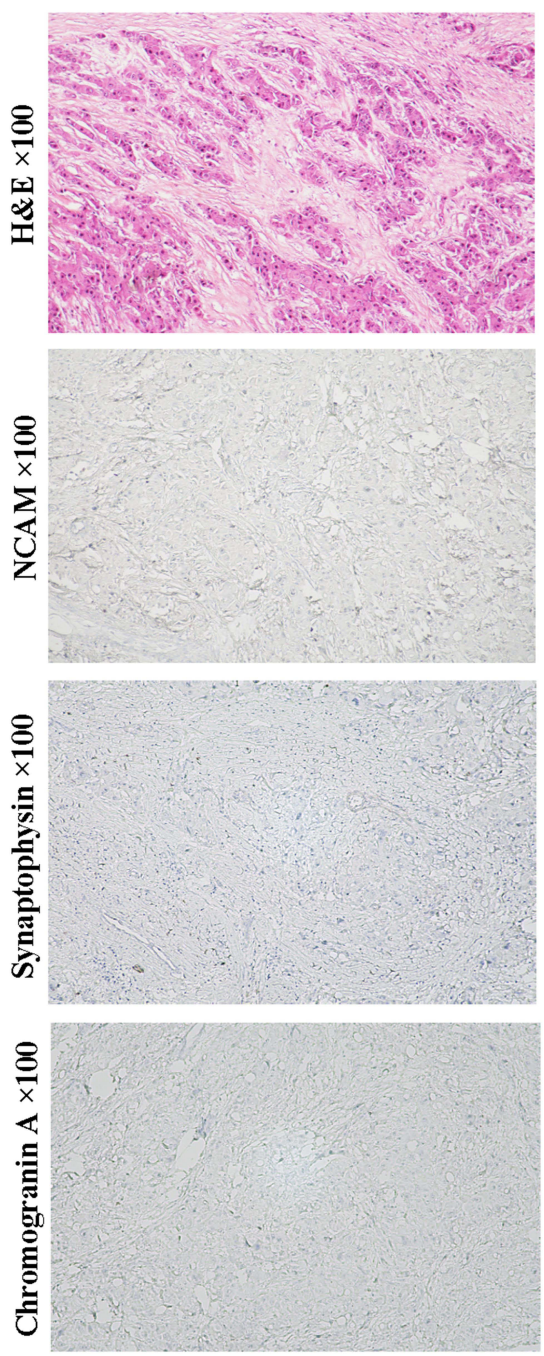
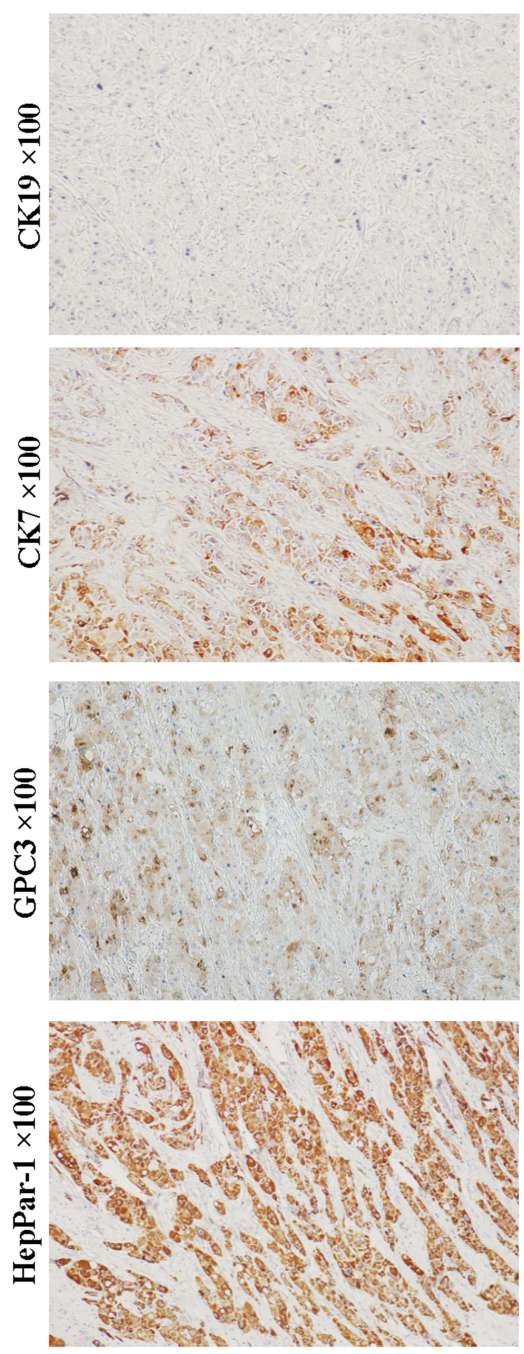
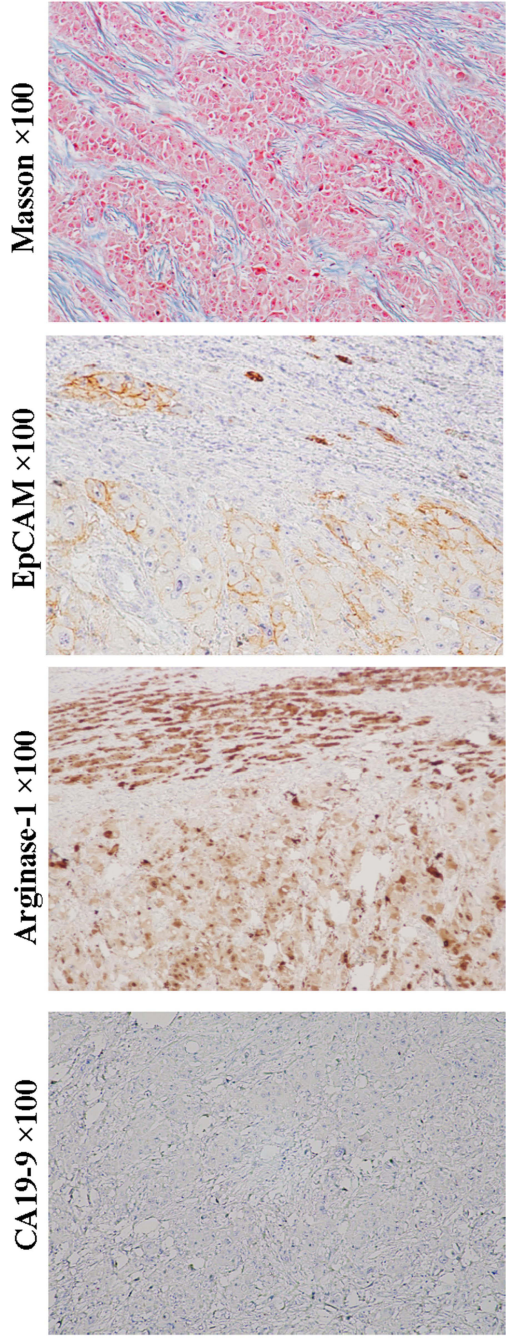

Figure 4 Example case of a fibrolamellar HCC originated from the later HCP. A 19-year-old female patient with $10.2 \mathrm{~cm}$ sized tumor in the left lobe of the liver. Her preoperative serum AFP was $118.6 \mathrm{ng} / \mathrm{mL}$. There was no recurrence in the first month after operation. Subsequently, the patient was lost to follow-up. H\&E and Masson staining show large polygonal tumor cells with copious eosinophilic cytoplasm and abundant fibrous stroma arranged in parallel lamellae around the tumor cells. Tumor cells do not express NCAM, chromogranin, synaptophysin, CKI9 and CAI9-9, but express CK7 and EpCAM, and hepatocytic lineage markers, GPC3, arginase-I and HepParI, suggesting that the tumor can originate from the later HCP.

cases, suggesting that this variant can be derived from the less committed stem cell of the liver prior to HPC.

In the 2019 WHO classification of tumors of the digestive system, an intermediate cell carcinoma that between HCC and ICC was mentioned. ${ }^{4}$ This variant is characterized by the presence of neoplastic cords, strands, and small trabeculae surrounded by fibrous stroma. Tumor cells coexpress hepatocytic and cholangiocytic biomarkers (HepPar-1+/AFP+/CK19+/CEA+). In terms of molecular phenotype, this pattern is consistent with that of HPCs/ hepatoblasts and early HCPs. If typical tubular structures are present, it should be considered to have originated from HPC, and therefore a diagnosis of combined HCC-
ICC may be appropriate. In the absence of morphological clues to ICC, histological and molecular manifestations can only support the early HCP-origin of this variant. Then, it should be classified as HCC.

In general, patients with combined HCC-ICC have worse clinical prognosis than patients with pure HCC.

\section{ICCs}

Cholangiocarcinoma is the second most common PETL with increasing diagnostic challenges. Anatomically, this tumor is divided into two types: ICC and extrahepatic bile duct carcinoma. ICC was further divided into mucinproducing and non-mucin-producing variants, which are 

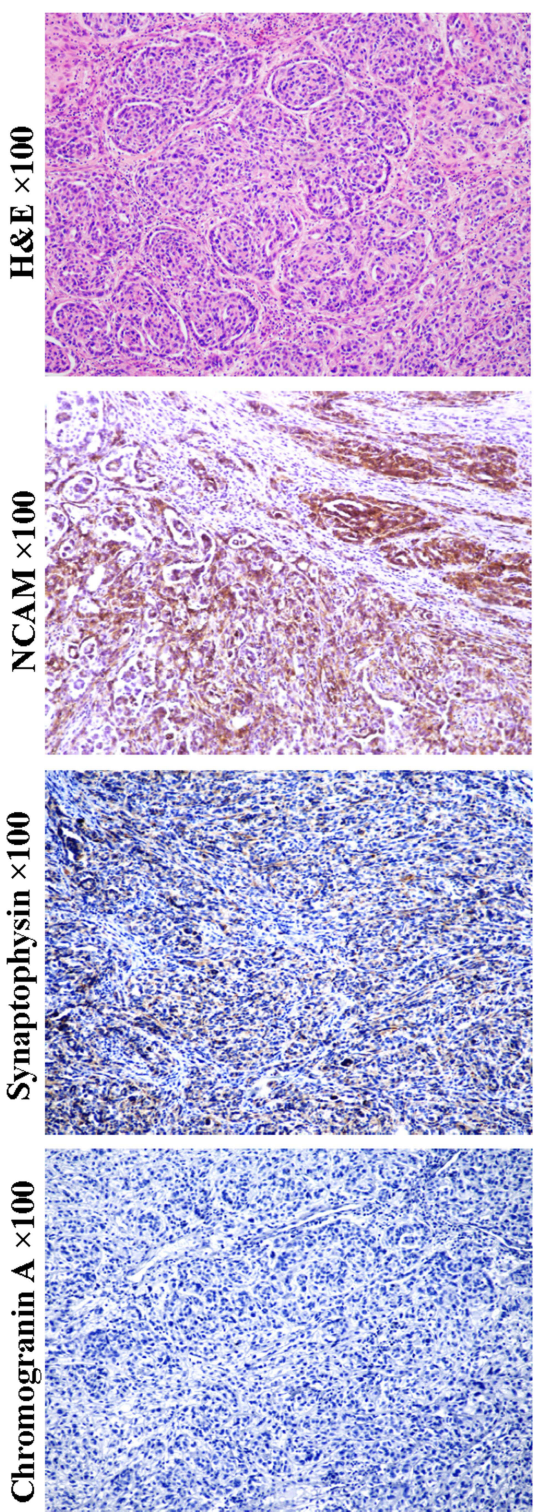
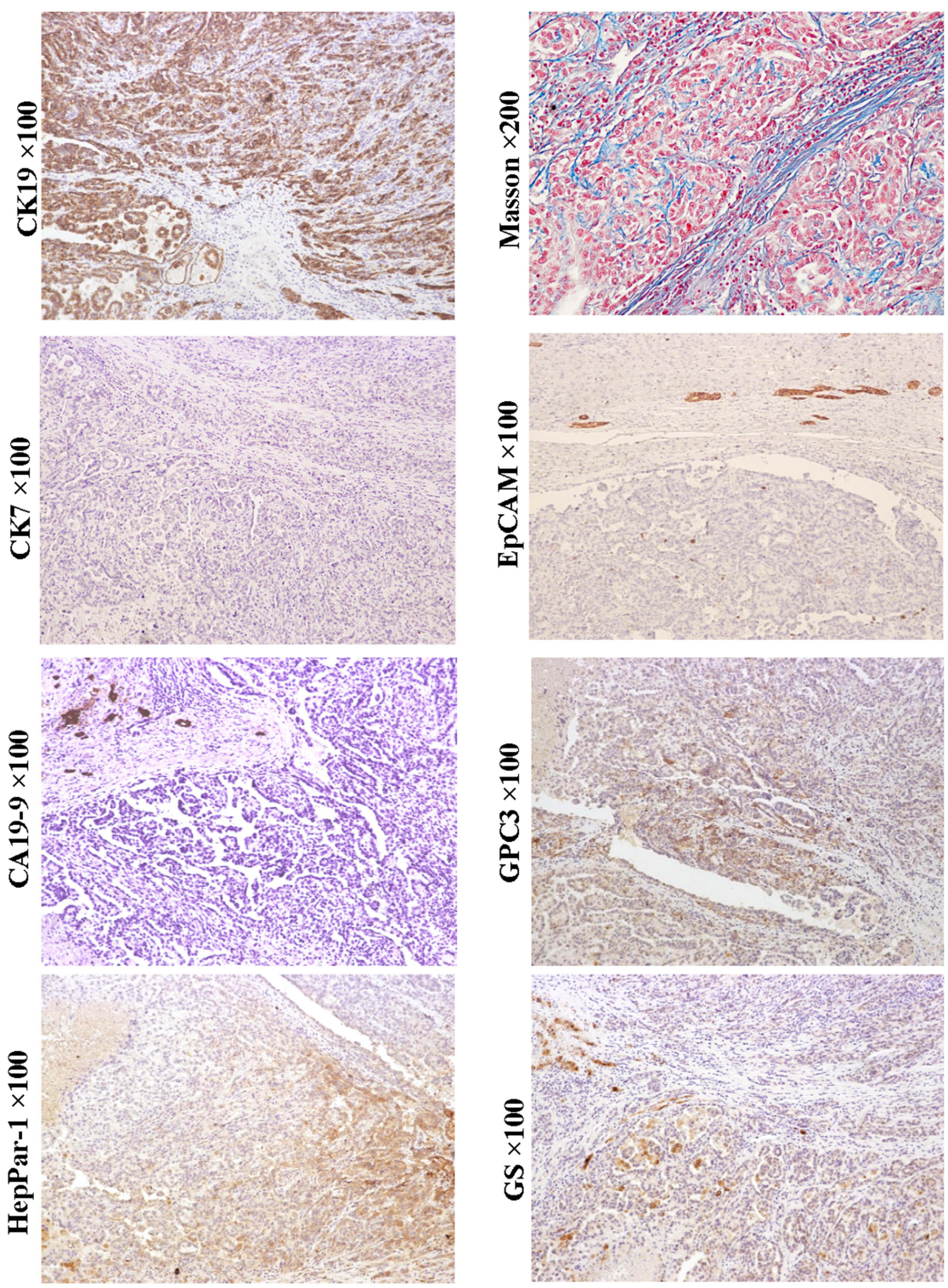
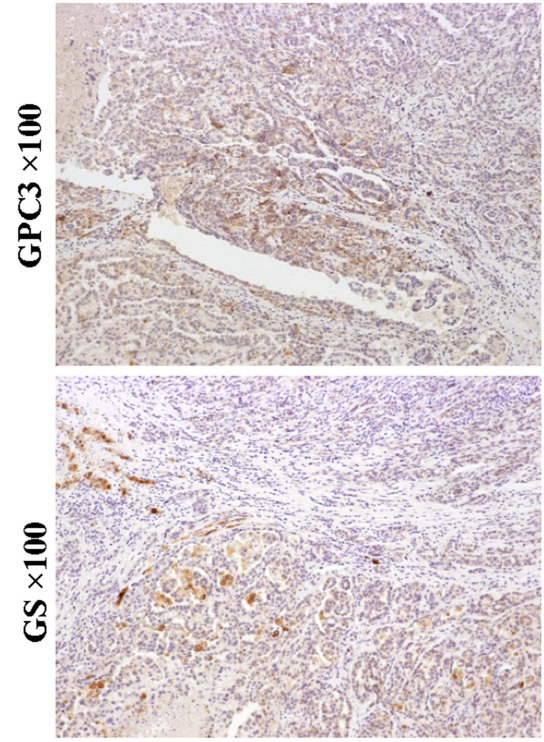

Figure 5 Example case of a CKI9+/GPC3+ HCC originated from the early HCP. A 51 -year-old male patient with $4.5 \mathrm{~cm}$ sized tumor in the right lobe of the liver. The patient has chronic hepatitis B infection. His preoperative serum AFP was $32.54 \mathrm{ng} / \mathrm{mL}$. Extrahepatic metastasis was found at $13 \mathrm{months}$ after liver transplantation. In CK 19 +/GPC3+ HCCs, the histology of tumor trabeculae or nests surrounded by fibrous stroma is very common. If tumors are composed of a large proportion of fibrous stroma, they may be classified as SHCC. In this case, tumor cells can express CKI9 and GPC3, glutamine synthetase (GS) and HepParl. They also express neuroendocrine marks, NCAM and synaptophysin (weak). Unlike the typical combined HCC-ICC, no ICC component was present in this subtype of HCC, and cholangiocarcinoma CAI9-9 was negative.

thought to correspond to anatomically large bile ducts and ductules, respectively. Tumor-associated mucins were only detectable in mucin-producing ICCs, whereas CK7 and CK19 were detected in both of the common variants. In terms of cellular origin, ICCs should be considered to be derived from the intrahepatic cholangiocytes of different differentiation stages.

ICC variant expressing stem cell markers once made classification of ICC controversial (Figure 8, D-PAS staining, magnification $\times 200$; Other staining, magnification $\times 100$ )
Histologically, this variant usually presents as tubular, striped and antler-like structures with the positive expression of NCAM, EpCAM, CK7 and CK19, whereas not HepPar-1 and GPC 3. ${ }^{4}$ Compared with conventional ICC (Figure 9, D-PAS staining, magnification $\times 200$; Other staining, magnification $\times 100$ ), this ICC variant has higher aggressiveness and worse clinical prognosis. ${ }^{3}$ In the 2019 WHO classification, this variant was classified as small duct-ICC category. More precisely, this ICC subtype may have originated from the early intermediate cholangiocytes (CCPs) due to 

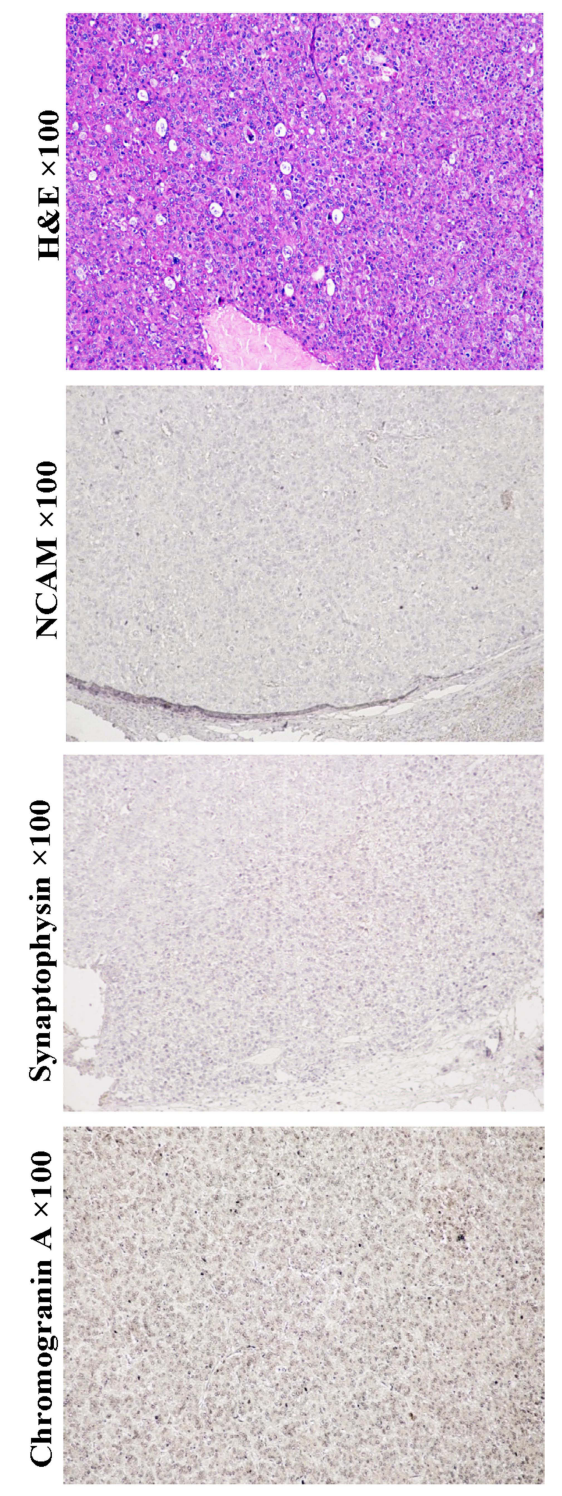
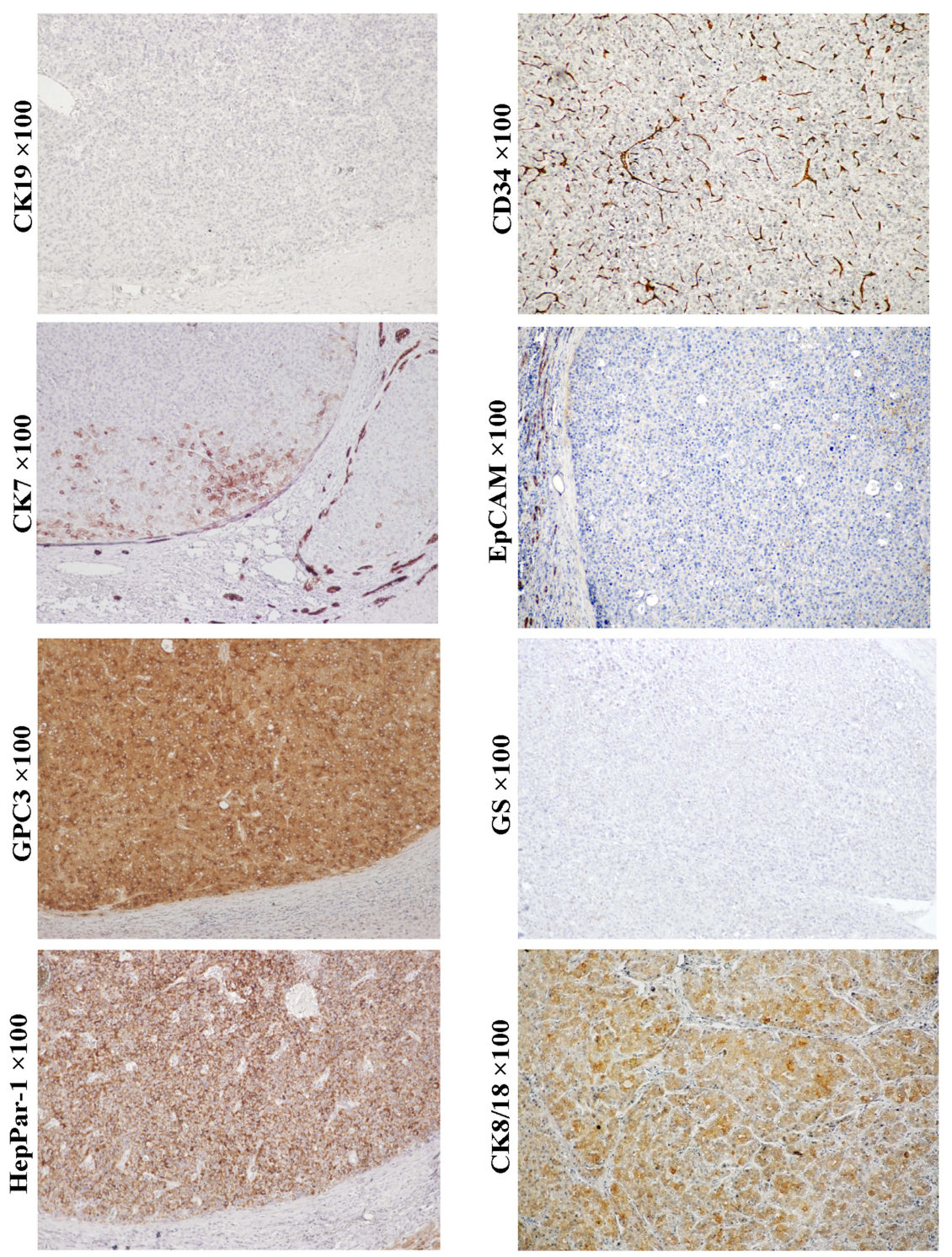

Figure 6 Example case of a CKI9-/GPC3+ HCC originated from the later HCP. A 42-year-old male patient with $1.5 \mathrm{~cm}$ sized tumor in the caudate lobe of the liver. The patient has chronic hepatitis B infection. His preoperative serum AFP was $57.13 \mathrm{ng} / \mathrm{mL}$. No tumor recurrence or extrahepatic metastasis occurred within 3 years after radical hepatectomy. Although the H\&E staining showed a compact form of HCC, the CD34 immunohistochemical staining clearly outlined the trabecular structure. Tumor cells uniformly express hepatocytic lineage markers GPC3, CK8/I8 and HepParl, but not neuroendocrine marks NCAM, chromogranin and synaptophysin. In addition, CK 19 expression was not detected in tumor tissues. However, in the cells of the periphery of the tumor nest or the front of infiltration, CK7 expression was detected, which was very similar to that of regenerating nodules in liver cirrhosis. These evidences suggested that this HCC case can originate from the later HCPs.

their similarities in morphological and molecular characteristics.

Benign intrahepatic bile duct lesions, such as bile duct adenoma and peribiliary cyst are well-known precursor lesions of cholangiocarcinoma. Recent studies reported that stem cell biomarkers can present in some of the benign tumors, ${ }^{65}$ suggesting that the benign intrahepatic bile duct tumors also have a pattern of multiple cells-of-origin. The malignant potential of these precursor lesions of cholangiocarcinoma need to be further explored.

\section{Hepatoblastomas (HBs)}

HBs are liver malignancies that preferentially develop in children. According to the 2019 WHO classification of tumors of the digestive system, HBs are classified as wholly epithelial and mixed epithelial/mesenchymal. Epithelial HBs are further divided into pure fetal, embryonal, macrotrabecular and small-cell undifferentiated. HBs have epithelial components similar to embryonal or fetal liver cells, and can also manifest as the histological and clinical features of HCCs. In recent years, reports of adult HBs have increased. The similarity of cell differentiation 

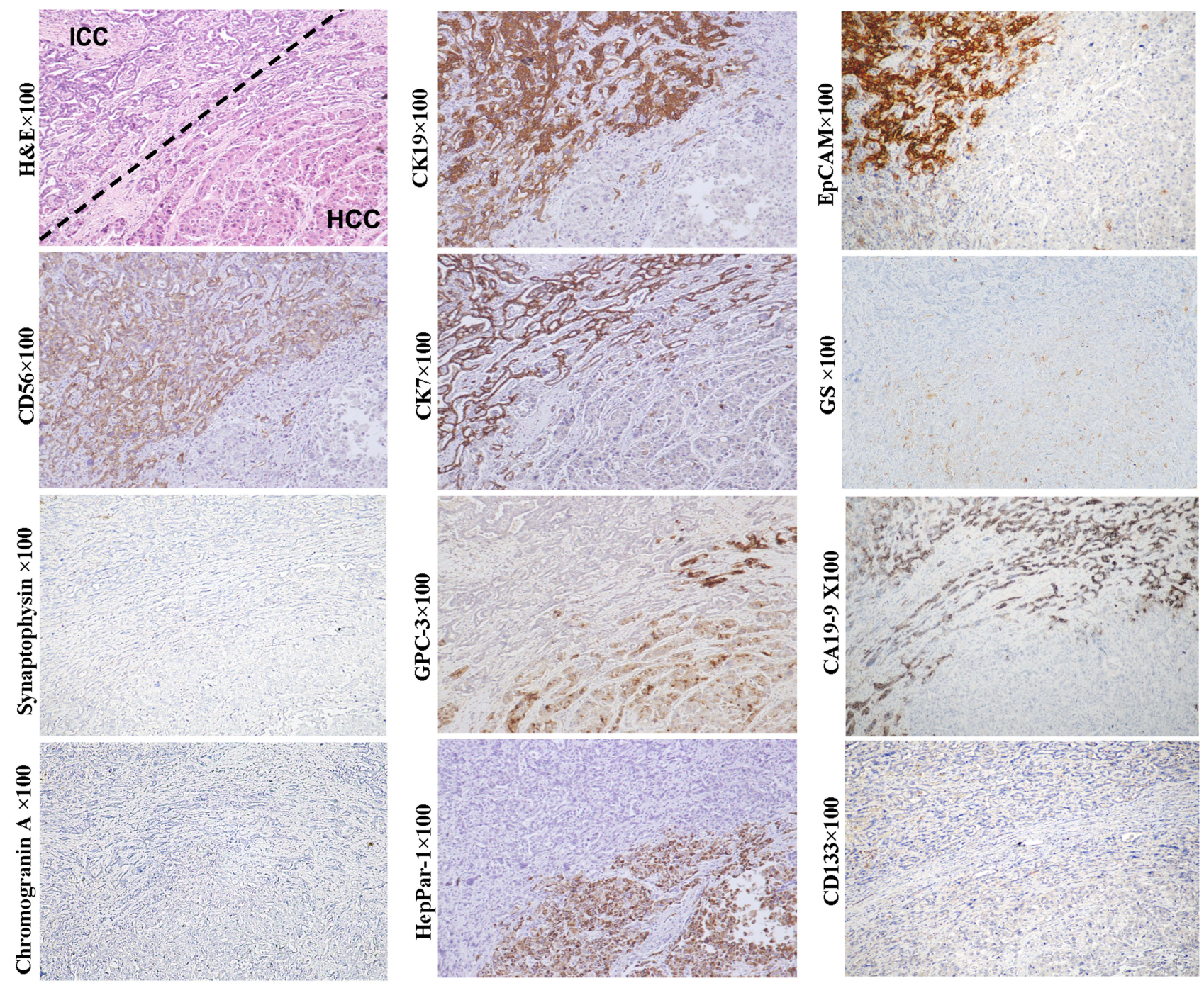

Figure 7 Example case of a combined HCC-CCA that can originate from the HPC. A 56-year-old male patient with $1.8 \mathrm{~cm}$ sized tumor in the right lobe of the liver. The patient has chronic hepatitis B infection. His preoperative serum AFP was $5.07 \mathrm{ng} / \mathrm{mL}$. No tumor recurrence or extrahepatic metastasis was found within 13 months of follow-up after liver transplantation. Above the dotted line is the ICC element, which is composed of small neoplastic lumens and cord-like structures that express CKI9, CK7, NCAM, EPCAM, and CAI9-9. Below the dotted line is the HCC element which is composed of neoplastic trabecular or nests that express GPC3, HepParl and CK7 (weak). In this case, the presence of two distinct HCC and ICC components suggests that the tumor originated from a bipotent HPC, although the transitional area cells between ICC and HCC elements is not well defined.

hierarchies and cell types between developing and regenerating liver prompts us to rethink the cellular origin of HBs.

Typical pure fetal HBs consist of homogeneous cells that grow as thin trabeculae or in sheets. The tumor cells of this subtype are smaller than normal hepatocytes in adults. Their cytoplasm can be clear or finely granular, reflecting variable amounts of glycogen and lipids, thus presenting a characteristic "light and dark" pattern. The histological features are similar to that of the developing fetal liver, which makes some scholars suspect that pure fetal HB may be derived from fetal stem cells. $^{66}$
Immunohistochemically, typical pure fetal HBs were usually negative for stem cell biomarkers C-kit, Thy-1 and NCAM, and with low or moderately serum AFP level. ${ }^{67-69}$ Beta-catenin is usually expressed on cell membranes in the same pattern as it is expressed in mature hepatocytes. ${ }^{4}$ In some cases, GPC3 can be expressed in neoplastic trabeculae and distributed along the bile canaliculus-like structure. This pattern is similar to the expression of GPC 3 in the developing hepatic plates of regenerative cirrhotic nodules and fetal livers, as well as in the neoplastic trabeculae of some welldifferentiated HCC (usually with low serum AFP level). The evidence suggests that the typical pure 

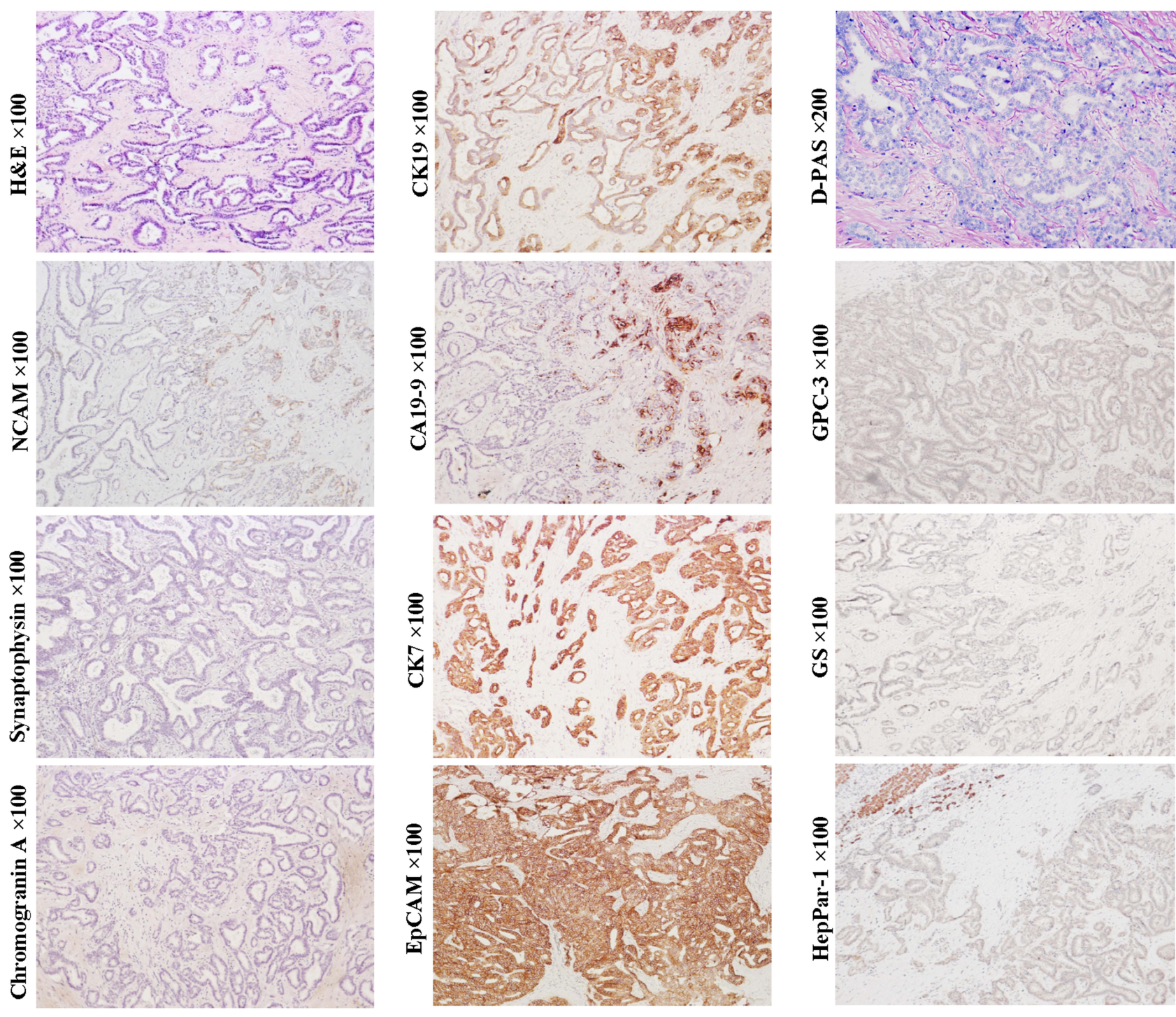

Figure 8 Example case of an ICC originated from the early CCP. A 72-year-old female patient with $4.0 \mathrm{~cm}$ sized tumor in the right lobe of the liver. The patient has chronic hepatitis B infection. The preoperative serum AFP and CA19-9 levels were $3.17 \mathrm{ng} / \mathrm{mL}$ and $25.63 \mathrm{ng} / \mathrm{mL}$, respectively. Tumor recurrence was found at the end of the second month after right hemihepatectomy. Tumor cells are arranged in tubular, striped and antler-like structures with the positive expression of EPCAM, CK 19, CK7, CA 19-9 and NCAM (scattered). Hepatocytic lineage markers GPC3 and HepParl, and neuroendocrine marks chromogranin and synaptophysin are not detected. Intracytoplasmic mucin was not found by D-PAS staining, indicating its ductule origin (non-mucin-producing ICC variant).

fetal HBs can originate from the near-mature or mature hepatocytes. In the case of similar morphology, EpCAM, CK19 and/or CK7 can be scattered expressed in some pure fetal HB, suggesting that HCPs may be the origin cells of these cases ${ }^{68}$ (Figure 10, magnification $\times 100$ ).

Based on the above evidence, we can conclude that pure fetal HBs and HCCs share the same spectrum of cells-of-origin (hepatocytic lineage cells). Compared with fetal HBs, HCCs usually have greater histological and cytological pleomorphism, which may be the result of regulatory confusion caused by the accumulation of more genetic and epigenetic variation during the long-term transformation of HCCs. However, most morphological features, such as solid sheets, "light and dark" pattern, trabecular structure, clear cell or chromophobe cell, etc can be shared by pure fetal HBs and HCCs, indicating that the former may closely resemble the latter. Except for the patients' ages of onset, the boundaries in morphology and cellular origin between the two may not be distinct. Comparing the genetic- and epigenetic-variation between pure fetal $\mathrm{HB}$ and the corresponding HCC that derived from the same differentiation hierarchy may help to further reveal the differences between them. At present, 

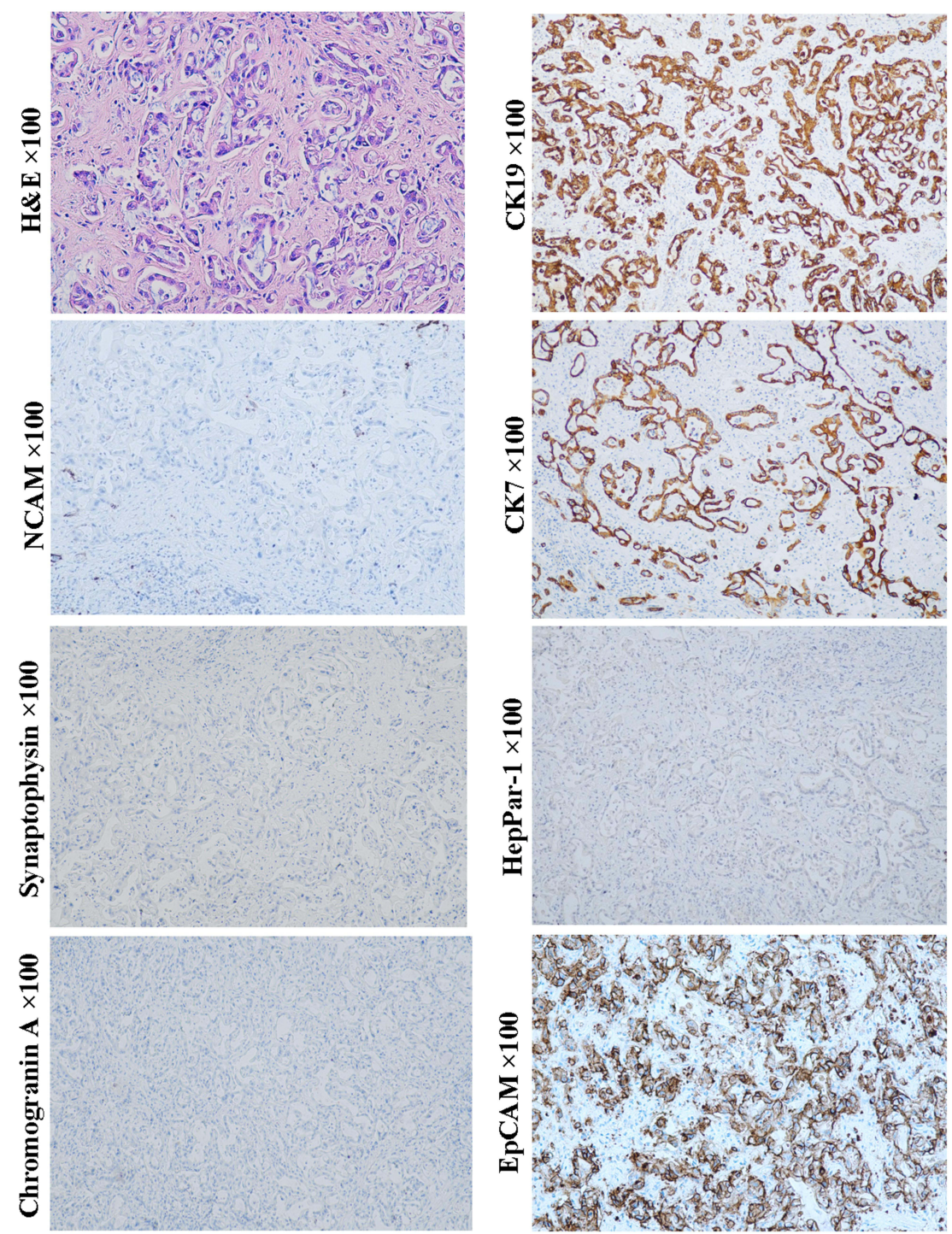
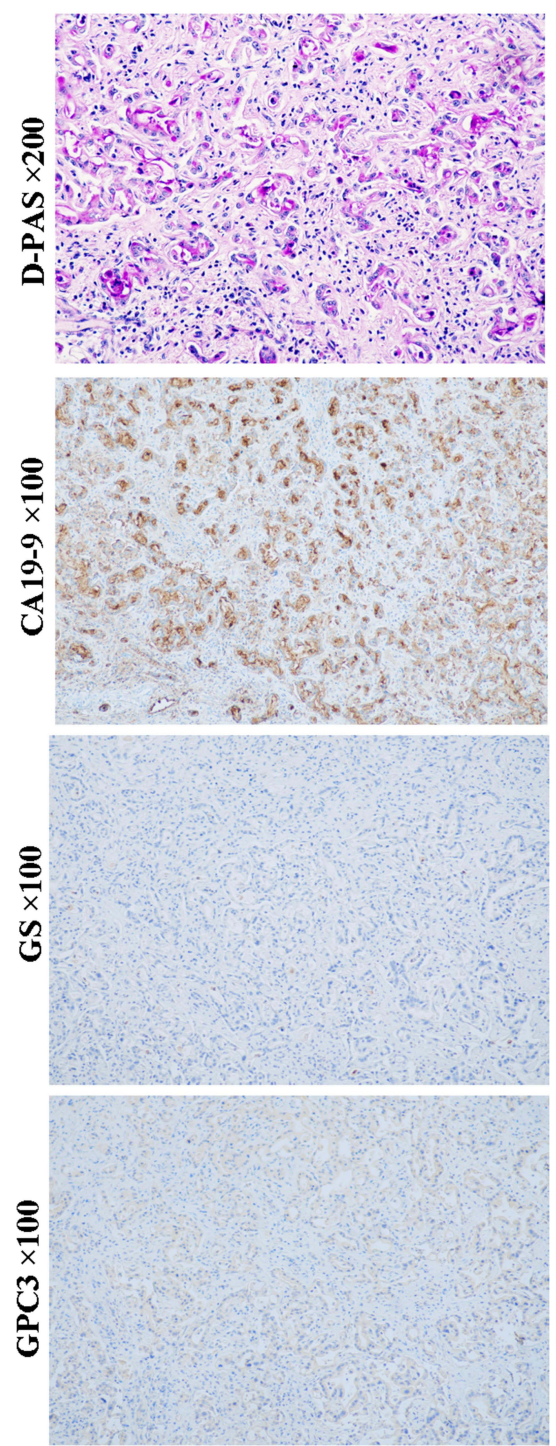

Figure 9 Example case of an ICC originated from the later CCP. A 69-year-old male patient with $4.4 \mathrm{~cm}$ sized tumor in the right lobe of the liver. The preoperative serum AFP and CAI9-9 levels were $5.4 \mathrm{ng} / \mathrm{mL}$ and $36.57 \mathrm{ng} / \mathrm{mL}$, respectively. Fourteen months after radical hepatectomy, intrahepatic tumor recurrence was found. Tumor cells are arranged in a striped pattern or tubular-like structure. D-PAS staining showed notable mucus secretion in the cytoplasm of tumor cells, indicating its large bile duct origin (mucin-producing ICC variant). In this case, tumor cells can express EpCAM, CA19-9, CK7 and CK19, whereas not neuroendocrine marks NCAM, chromogranin and synaptophysin, and hepatocytic lineage markers GPC3 and HepParl, which is generally consistent with that of the later CCP.

the influence of the cellular origin on the biological behavior and clinical outcomes of pure fetal HBs have not been systematically investigated. Sub-classification of pure fetal HB at the molecular level may be of great significance for individualized treatment of this tumor in the future.

Embryonal HBs were also nominated as mixed embryonal and fetal HBs because both embryonal and fetal components mostly co-exist in this subtype (Figure 11, H\&E staining, magnification $\times 400$; AFP IHC staining, magnification $\times 200$; Other staining, magnification $\times 100$ ) The morphological and molecular characteristics of fetal component are similar to those of pure fetal HBs. Since the transition between embryonal and fetal components is often observed, the former is considered to be the precursor of the latter. ${ }^{69}$ The histology of embryonal component varies greatly. Less-differentiated tumor cells can be arranged in loosely cohesive sheets that mimic the structures of the developing hepatic plate. The pseudorosettes/ acinar patterns around a central lumen can mimic the structures of the developing ductal plate. ${ }^{70}$ Immunohistochemically, these embryonal components usually show a CK7+/CK19+/CK8+/CK18+/EpCAM $+/ \mathrm{GPC} 3+/ \mathrm{AFP}+$ pattern, just like that of hepatoblasts, 

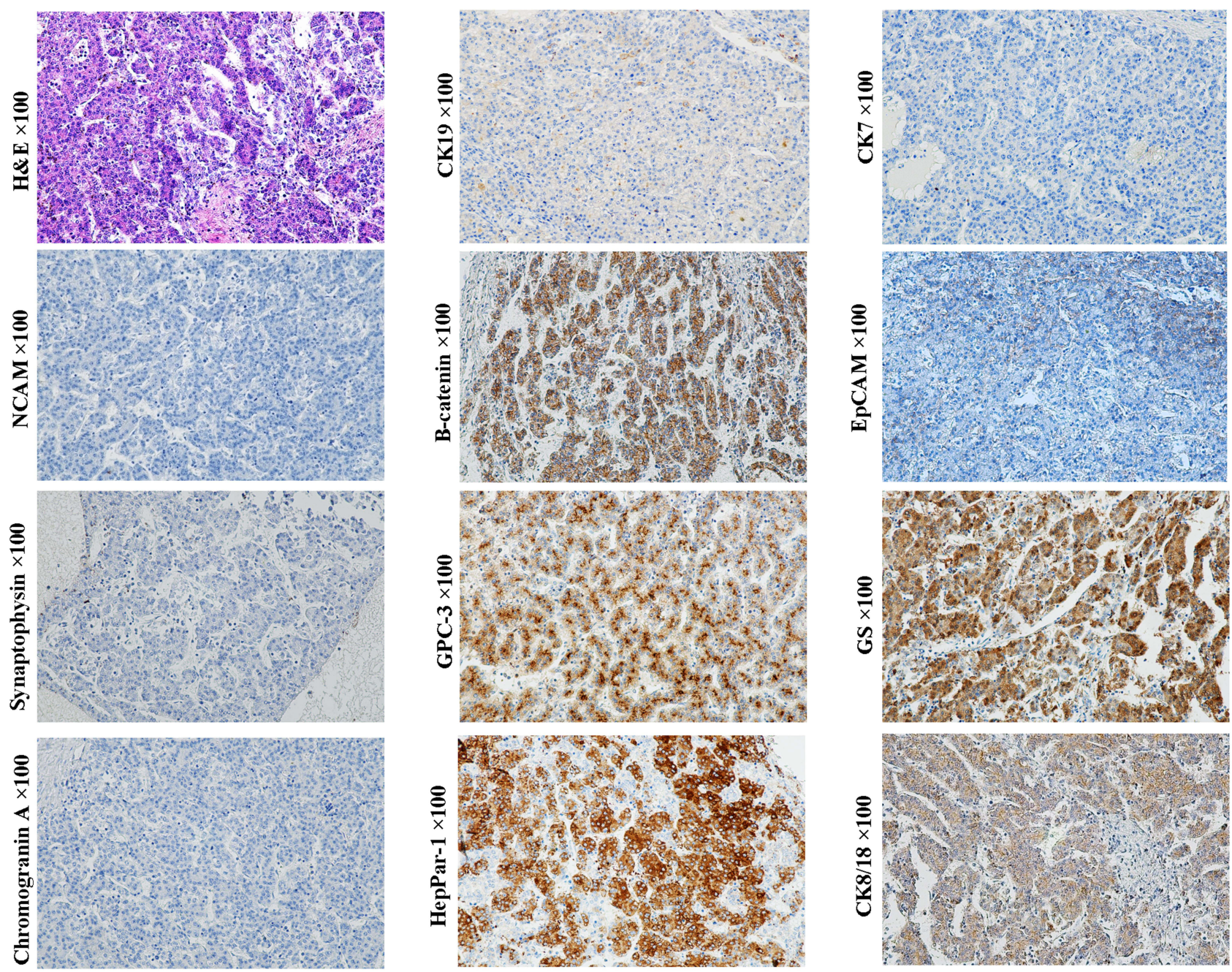

Figure 10 Example case of a pure fetal HB originated from the HCP. A I-year-old female patient with II cm sized tumor in the right lobe of the liver. The preoperative serum AFP level $>1210 \mathrm{ng} / \mathrm{mL}$. Lung metastasis was found at 18 months after extended right hemihepatectomy. Homogeneous tumor cells are arranged in trabecular or acinar patterns, which closely resemble an HCC. Tumor cells express CK8/I8, GPC3, $\beta$-catenin (cell membrane) and CKI9 (scattered), but not NCAM, chromogranin, synaptophysin, CK7, and HepParl. EpCAM is negatively stained in the typical thin trabecular structure, while it is expressed in the cell membrane in the adjacent small cell crowded area. Glutamine synthetase is expressed dispersedly. This immunohistochemical profile is consistent with that of the HCP, whereas not hepatoblast or HPC.

HPC, and early HCPs. ${ }^{71-76}$ The presence of tubular structure indicates that these cases may closely resemble the combined HCC-ICC. ${ }^{70}$ In some patients, undifferentiated small cell component with a molecular profile similar to that of LSC can appear, suggesting that these cases may originate from the less committed stem cells prior to hepatoblasts/HPCs, which will be further discussed in the following small cell undifferentiated HBs section.

Macrotrabecular HB is characterized by five or more cells-thick trabeculae. ${ }^{77}$ Since the presence of the macrotrabecular structure is always associated with the epithelial $\mathrm{HBs}$, this $\mathrm{HB}$ variant is currently considered to be a growth pattern rather than a subtype of HB. Except for the number of cell layers that constitute the tumor trabecula, there is no clear morphological difference between the macrotrabecular structure of $\mathrm{HB}$ and the thick trabecular structure of HCC. Zimmermann reported that the cells constituting the macrotrabeculae were intertumor heterogeneous. They may be fetal, embryonal, or pleomorphic. ${ }^{78}$ At present, there is little reliable information about the clinical outcomes of this HB variant.

Typical small cell undifferentiated HBs (SCUHBs) (Figure 12, magnification $\times 100$ ) are composed of a fairly uniform small cells that lack evidence of epithelial or stromal differentiation by hematoxylin-eosin staining. The existing literature shows that most SCUHBs do not express HepPar-1, GPC3, CK19 and CK7, but variably express the neuroendocrine markers NCAM, chromogranin, or the mesenchymal marker vimentin. Almost all cases showed positive expression of CK8/18. ${ }^{71,77-79}$ The 

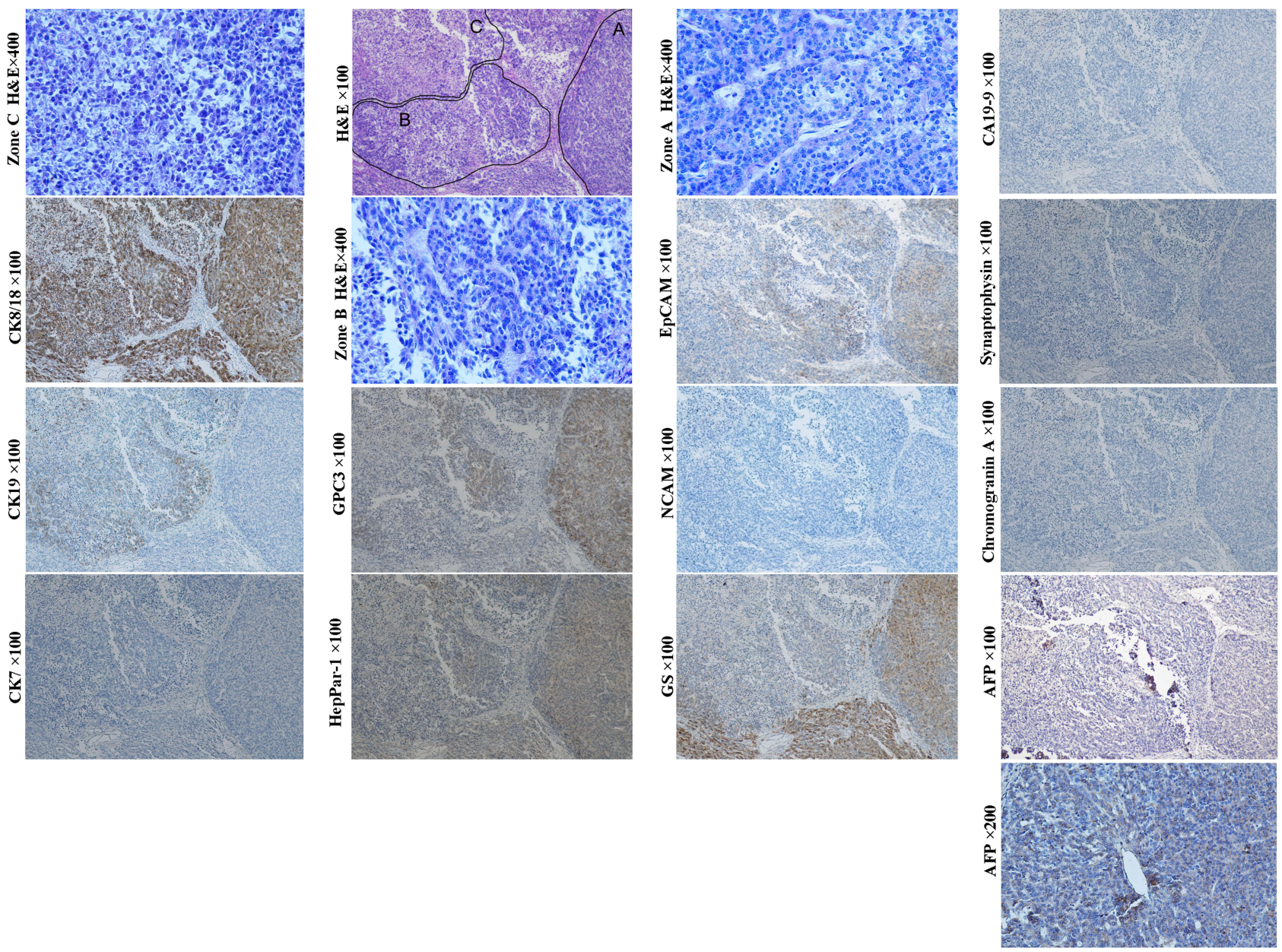

Figure II Example case of an embryonal HBs. A 7-month-old male patient with $8.0 \mathrm{~cm}$ sized tumor in the right anterior lobe of the liver. The preoperative serum AFP level> 10,000 ng/mL. Tumor recurrence was found 3 months after wedge resection. H\&E staining revealed three distinct morphologic regions. Tumor cells of zone $A$ are arranged in trabecular pattern with positive expression of GPC3, glutamine synthetase, HepParl, CK8/I8 and EpCAM (weak), but not CKI9, CK7 and neuroendocrine biomarkers, which is manifested as histological and molecular features of a fetal HB. Tumor cells of zone B are arranged in cords, acinar or pseudorosettes structures with the expression of CK I9, EpCAM and hepatocytic biomarkers, indicating that they are embryonal component. Tumor cells of zone C are composed of almost all small cells that were arranged in loosely cohesive sheets (small cell element). They do not express almost all of the biomarkers tested, except for CK8/I8 (diffusely) and CK 19 (focally). The phenotype of the small cells is consistent with that of the LSCs. Of note, there are transition between zone B and C, suggesting that cells of zone C can be the precursor of zone $\mathrm{B}$.

serum AFP levels in SCUHBs are usually normal or only slightly elevated. ${ }^{65}$ This molecular profile is almost the same as that of LSCs. In addition, there are reports showing that some SCUHBs express CK19, suggesting that they can originate from transitional cells between LSCs and hepatoblasts. Adult SCUHBs have also been reported, and their molecular phenotype is similar to that of children, indicating that LSCs reside in children or adults may be their common cells-of-origin. The picture of the uniform composition of small cells and the lack of other epithelial component in SCUHBs may be due to differentiation arrest. Notably, small cells can be a component of some embryonal HBs, and transitions between the small- cell undifferentiated areas and the epithelia areas can be observed, suggesting that small cells may be precursors of other components. ${ }^{78}$ The existence of teratoid hepatoblastoma and mixed epithelial/mesenchymal HBs can be a manifestation of multiple differentiation potential of TICs derived from the LSCs or even less committed extrahepatic pluripotent stem cell, as hematopoietic stem cells and mesenchymal stem cells are reported to contribute to liver regeneration. ${ }^{79}$

HBs can originate from a variety of cells and be mapped to the different differentiation hierarchies of normal liver parenchymal cells. Although nominated as hepatoblastoma, some of its subtypes do not originate from actual 

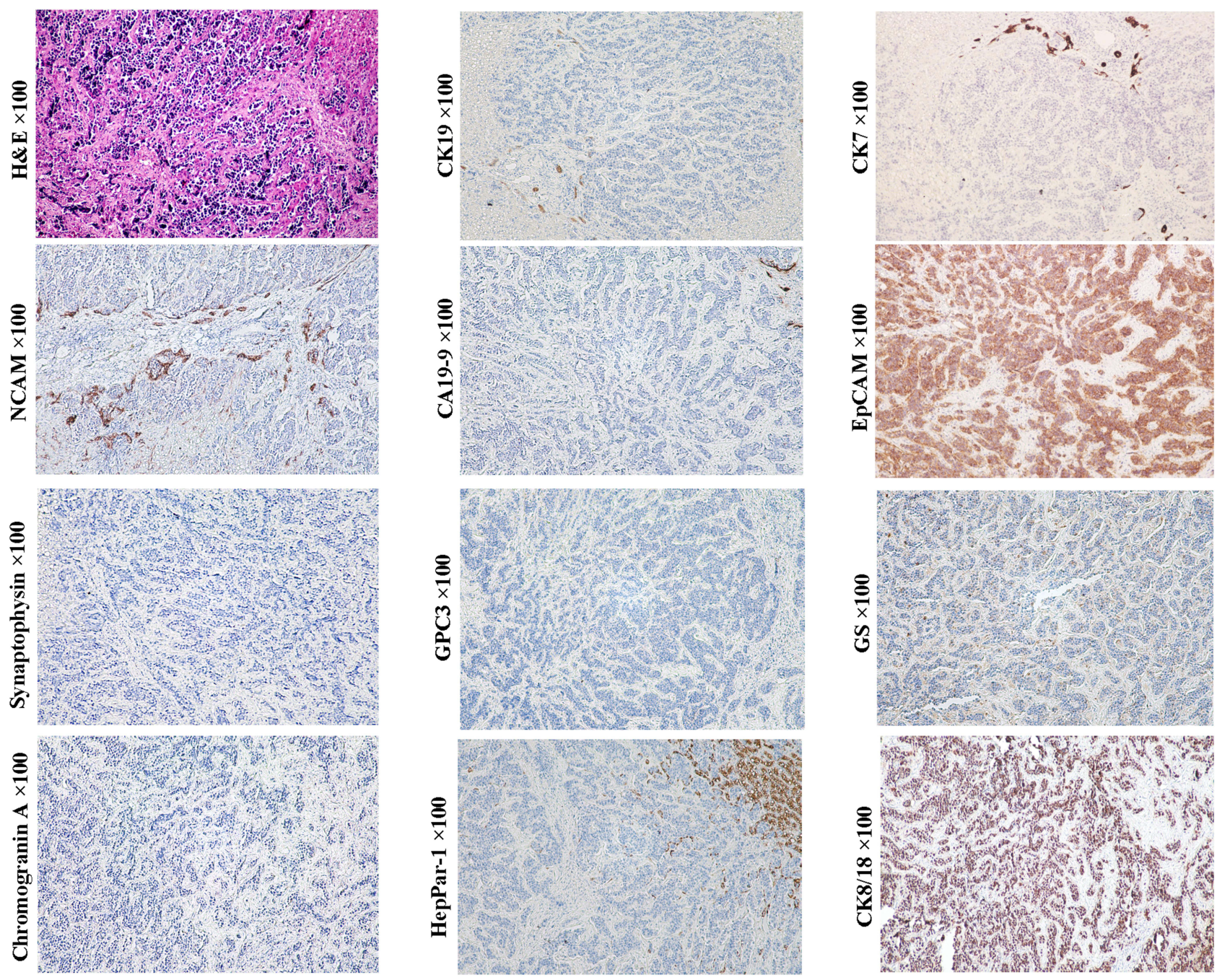

Figure 12 Example case of a typical small cell undifferentiated HBs. A 16-year-old female patient with multiple nodules in the right lobe of the liver. The diameter of the larger nodule was $8.0 \mathrm{~cm}$. Only one nodule with a diameter of $2 \mathrm{~cm}$ was excised for pathological examination. The preoperative serum AFP and CAI9-9 levels were 2.34 ng/ $\mathrm{mL}$ and $39.23 \mathrm{ng} / \mathrm{mL}$, respectively. Tumor cells looked like lymphocytes, but clustered and were somewhat larger that are separated by fibrous stroma. This histological appearance is very similar to that of small cell carcinoma of the lung. Tumor cells express NCAM (preferentially distributed in the front of infiltration), EpCAM, CK8/I8 and glutamine synthetase (scattered), but not chromogranin, synaptophysin, CK19, CK7, GPC3 and HepParl, which is consistent with that of the LSCs.

hepatoblast. In children, some subsets of HBs have the similar histological and molecular characteristics as that in adult liver epithelial malignancies. Thus, the boundaries between HBs and other epithelial malignancies of the liver are not distinct. The histological classification of HBs is associated with the patient's outcome. It is reported that some well-differentiated fetal HBs is surgically curable, much like that of well-differentiated HCCs. The prognosis of the other subtypes of HBs is unfavorable.

\section{Primary Hepatic Neuroendocrine Tumors (PHNETs)}

Neuroendocrine neoplasms are heterogeneous group of neoplasm have been thought to originate from neuroendocrine cells located throughout the body. The majority of neuroendocrine tumors (NETs) are gastrointestinal or respiratory in origin. PHNETs are a rarity and represents about $0.3 \%$ of all neuroendocrine tumors (Figure 13, magnification $\times 100$ ). It was previously thought that PHNETs may originate from hepatic stellate cells, ectopic pancreatic or adrenal tissue, or be the dedifferentiation products of parenchymal cells in liver. Over the past few years, new discoveries have led to the idea that PHNETs' cellular origin may be HPCs. ${ }^{24,80}$ As shown in Tables 2 and 3, many types of liver parenchymal cells, including LSCs, hepatoblasts/HPCs and early HCPs and early CCPs have neuroendocrine characteristics. So, we speculated that tumors derived from these cells could have sustained neuroendocrine potentiality through epigenetic inheritance. 


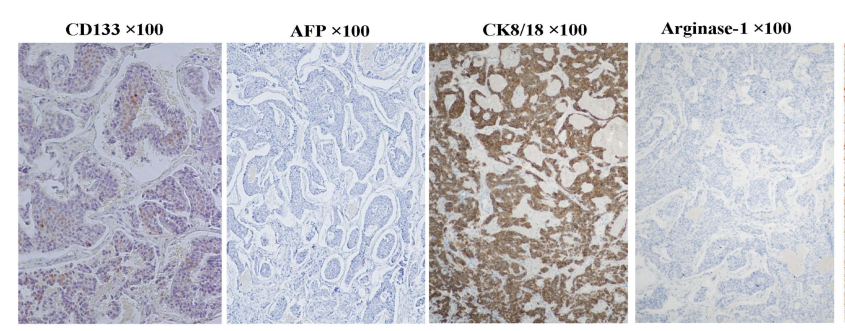

CT image in contrast-enhanced arterial phase

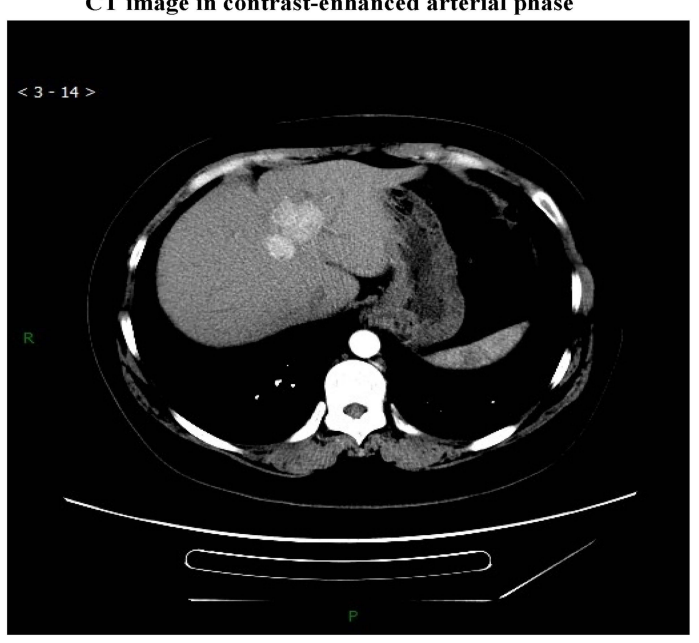

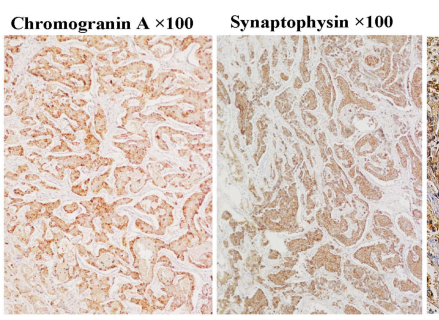

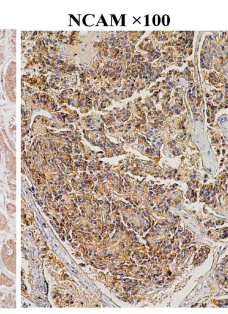

CK7 $\times 100$
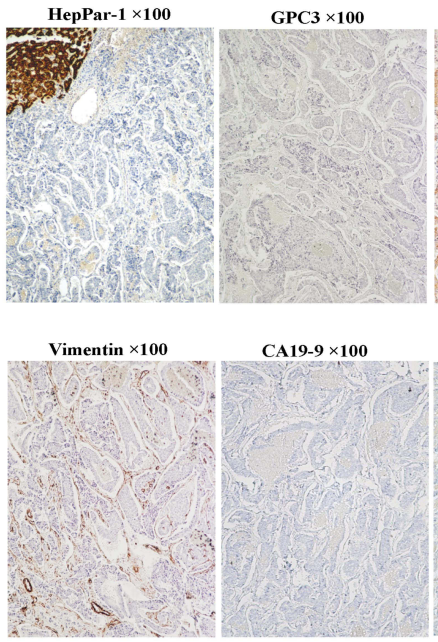

CA19-9 $\times 100$

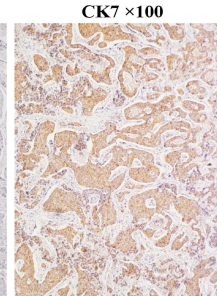

GS $\times 100$

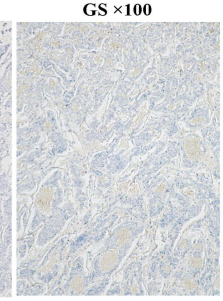

H\&E $\times 100$

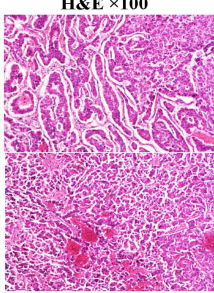

CK19 $\times 100$

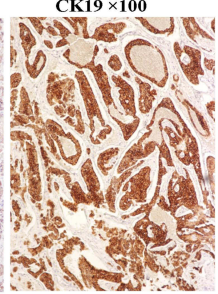

EрCAM $\times 100$

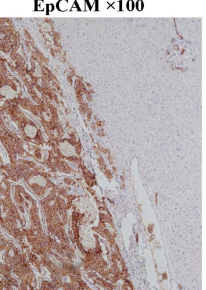

Figure 13 Example case of a primary hepatic neuroendocrine carcinoma. A 40-year-old female patient. Contrast-enhanced CT scan showed multiple nodules with clear boundaries in the lateral left lobe and anterior right lobe of the liver. The diameter of the larger nodule was $3.1 \mathrm{~cm}$. The preoperative serum AFP and CAI9-9 levels were $1.01 \mathrm{ng} / \mathrm{mL}$ and $7.19 \mathrm{ng} / \mathrm{mL}$, respectively. Tumor recurrence was found at 9 months after extended left hemihepatectomy. Tumor cells are round, oval or polygonal, small in size, eosinophilic in cytoplasm, and increased in nuclear-to-cytoplasmic ratio, arranged in acini, cords, trabeculae, or pseudorosettes. Tumor cells can express chromogranin, synaptophysin, NCAM, EPCAM, CK8/I8, CK7 and CK 19, but not hepatocytic lineage markers, GPC3, AFP, glutamine synthetase, arginase-I and HepParI, and cholangiocytic marker CAI9-9.

The 2019 WHO classification of tumors of the digestive system divides PHNET into NETs, neuroendocrine carcinomas (NECs) and mixed neuroendocrine-nonneuroendocrine neoplasms (MiNEN) three categories. ${ }^{4}$ So far, most of the reports on NECs are small cell NECs. The morphology and molecular phenotype of this small cell $\mathrm{NEC}$ is almost the same as that of SCUHB,${ }^{80-83}$ suggesting that LSC may be the cellular origin of these tumors. In the previously reported hepatic NETs, multiple architectures, such as trabecular, insular/nests, cords, ribbons, pseudopapillary or acinar patterns were observed. Despite the variation, these architectures with cytological features of neuroendocrine can also be found in HCCs and HBs, indicating that these hepatic NETs can overlap with certain subtypes of HCCs and HBs. In addition, some hepatic NETs with the similar histological and molecular characteristics to the well-differentiated NETs of the upper digestive tract and pancreas were reported. Given the multipotential of LSC, we suspect that these tumors can be transformed from the descendants of LSCs that differentiate towards the upper digestive tract or pancreas lineages.
Chromogranin and synaptophysin are universal markers of neuroendocrine cells, so their expression has been used as important diagnostic evidence for neuroendocrine tumors. However, their expression is variable in multiple PETLs, including PHNETs, which once puzzled us. Some previous studies have shown that chromogranin was more inclined to be detected in the PETLs that are rich in fibrous stroma, such as FLHCC (CK7+), SHCC (CK19+), combined HCC-ICC, and hepatoblastoma, in addition to ordinary HCC ${ }^{84-88}$ A research from Tania Roskams showed that the co-existence of basement membrane components collagen type IV and matrix heparan sulfate proteoglycan (HSPG) perlecan is essential for the expression of chromogranin in HPC. When cultured on a medium containing collagen type IV and HSPG perlecan, chromogranin can be induced to be expressed in two bile ductular epithelial cell lines A16 and $\mathrm{H} 1 .^{24}$ Their results suggested that even with neuroendocrine potentiality, cells still need stromal components to induce chromogranin expression, which may explain why chromogranin tends to be detected in PETLs rich in fibrous mesenchyme. Still, another neuroendocrine 
marker NCAM can be detected in a variety tumor of PETL family, including PHNETs, indicating its significant role in judging the cellular origin of these tumors. ${ }^{56}$ Hepatic MiNEN found in adults is usually composed of small cell NEC and HCC, which is reminiscent of the HCC components present in small cell HBs. ${ }^{78}$ According to the molecular expression profile, the NEC component in MiNEN is most likely precursor of HCC component.

In brief, almost all PETLs family members with stem cell characteristics can have neuroendocrine potentiality. Small cell NECs of the liver and SCUHBs may have the same or similar cellular origin from LSCs that can be characterized by the expression of CK8/18 and NCAM. Other primary hepatic NETs or NECs can variably overlap with other PETLs that transformed from the different differentiation stages and lineages epithelial cells with neuroendocrine characteristics.

\section{Discussion and Perspective}

In this work, cellular origins of some major members of PETL family in pediatric and adult were re-evaluated. As summarized in Figure 14, our results suggest that, 1) HCAs, HCCs and pure fetal HBs share the same spectrum in their cellular origin including the HCPs and their differentiated descendants. 2) Bile duct adenomas, peribiliary cysts and ICCs can share the same spectrum in their cellular origin including the CCPs and their differentiated descendants. 3) The cells-of-origin of embryonal HBs include LSCs, hepatoblasts, and transitional cells between them. Embryonal HB with small cell element, SCUHB and small cell NEC of the liver can have the same or similar cells-of-origin from LSC. Embryonal HB lacking the small cell component of the LSC phenotype and presenting both hepatocytic and bile duct/ductule components may originate from actual hepatoblasts/HPCs as the combined HCCICC does. 4) Teratoid hepatoblastoma and mixed epithelial/ mesenchymal HBs can be derived from the LSCs or even less
PHNETs similar to NETs in the upper digestive tract and pancreas:
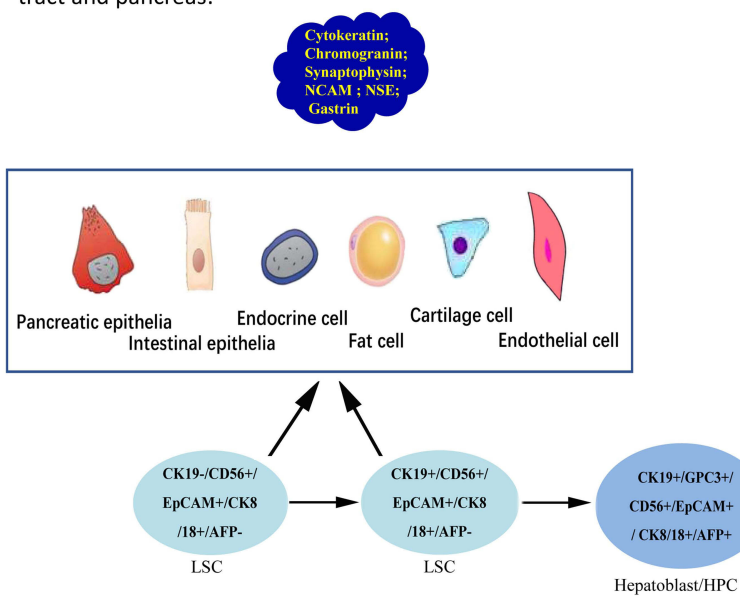

Tumors derived from the LSC, hepatoblast or HPC:
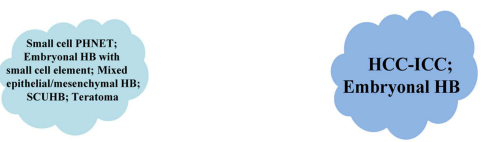

Tumors derived from the cholangiocytic lineage:
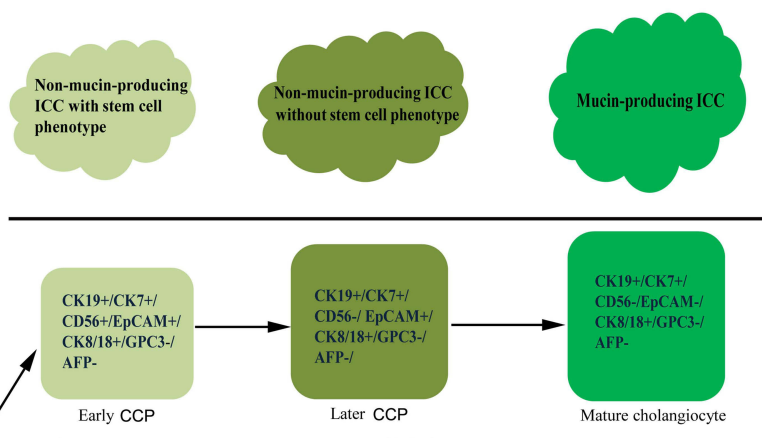

Early CCP

Cholangiocytic committed progenitors (CCP) (Non-mucin-producing)

Mucin-producing cholangiocyte

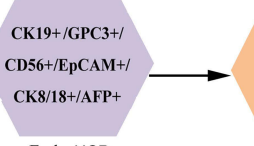

Early HCP

Hepatocytic committed progenitors (HCP)

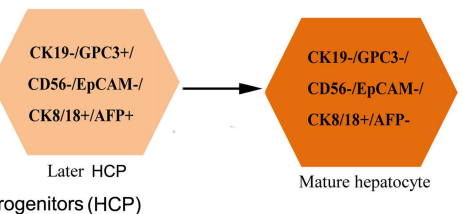

Tumors derived from the hepatocytic lineage:
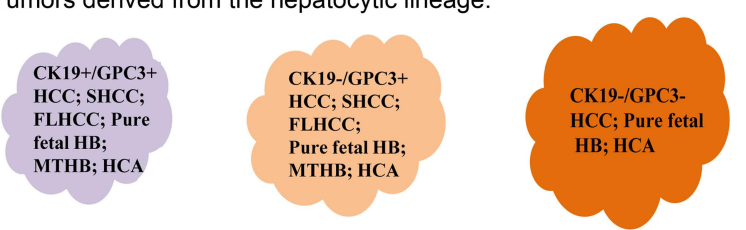

Figure 14 The cellular origins and the lineage relationships of the primary liver epithelial tumors. In liver, the heterogeneity of the cellular origin of tumors is not chaotic. By referring to histopathological features and differentiation lineages- and stages-related biomarkers, cellular origins of the vast majority of tumors or their subtypes can be traced. 
committed extrahepatic pluripotent stem cell. 5) Many members of the PETLs family, including those derived from LSCs, hepatoblasts/HPCs, early HCPs and early CCPs have neuroendocrine potentiality. Except for those PHNET exhibit hepatocytic and/or cholangiocytic phenotypes, other PHNETs subtype may be derived from the descendants of LSC that differentiate towards the upper digestive tract, pancreas or other lineages.

The significance of tracing the cell origin of tumors goes beyond classification, as more and more studies in recent years have shown that signaling pathways or molecules associated with normal tissue development and cell differentiation in tumors are potential therapeutic targets. For example, many pivotal signaling pathways, such as the Notch, Hedgehog, Wnt/ $\beta$-catenin pathways, as well as genes, such as HMGA2, Bcl-2, Bmi-1, Ras, C-myc, and HIF1- $\alpha$, that regulate normal stem cell self-renewal, differentiation, and survival are connected with tumor stem cell. ${ }^{89-94}$ In different systems, the expression of some tumor associated molecules, such as histone deacetylase, DNA methyltransferases, vascular endothelial growth factor receptors and PD1/PD-L1,${ }^{95-101}$ are related to the cellular origin of tumors. Scattered literature implies that the invasiveness of tumor stem cells may be related to the innate state of key signaling pathways or genes from normal counterpart origin cells through epigenetic memory during the transformation. ${ }^{102-104}$ In symmetrical division of normal cells, accurate parental histone recycling preserves positional information and allows post-translational modifications transmission to daughter cells. ${ }^{105}$ Just like normal cell self-renewal, cell division is also a way for tumor-initiating cells to be transformed. Although enough driver gene mutations can initiate transformation, they may not cause a disruptive change in tumor epigenetics. Therefore, epigenetic memory in transformation may be one of the important mechanisms by which tumor-initiating cells maintain biological characteristics of their corresponding normal origin cells.

Traditionally, we have traced the origin of tumors based on the limited lineage and stage-related markers of normal tissues or cells. Recent few years, advances in new technology, such as high-density single-cell mRNA sequencing, have made it possible to demonstrate cellular origin and helps detect known oncogenic drivers of liver malignancies. ${ }^{106-109}$ In future, an indepth understanding of the epigenetic landscapes underlining global patterns of gene expression in different kind of liver parenchymal cells will enable us to accurately depict the essential characteristics of tumors, which is expected to open a new path for tumor classification, prognosis assessment and new target discovery.
There are some limitations to this work. Firstly, genetic and epigenetic determinants are likely to interact in shaping the hallmarks of tumors. Future work should focus on the extent to which genetic and epigenetic determinants synergistically confer aggressive biology on tumors. Second, due to the lack of relevant information, some orphan types of PETLs were not included in this work. The international cooperation will facilitate the integration of new parameters and will promote us to move towards a precise classification and individualized treatment scheme in the future.

\section{Abbreviations}

PETL, the primary epithelial tumors of the liver; WHO, World Health Organization; TIC, tumor-initiating cell; NOC, normal origin cell; HB, hepatoblastoma; HCC, hepatocellular carcinoma; HCP, hepatocytic-committed progenitors; $\mathrm{CCP}$, cholangiocytic-committed progenitors; ICC, intrahepatic cholangiocellular carcinoma; LSC, liver stem cell; CK, cytokeratin; GPC3, glypican 3; GS, glutamine synthetase; NCAM, neural cell adhesion molecule; AFP, alpha-fetal protein; HepPar1, hepatocyte-paraffin antigen 1; EpCAM, epithelial cell adhesion molecule; DP, ductal plate; HPC, hepatic progenitor cell; HCA, hepatic adenoma; $\mathrm{HNF} 1 \alpha$, hepatic nuclear factor $1 \alpha$; SHCC, Scirrhous HCC; FLHCC, fibrolamellar HCC; SCUHB, small cell undifferentiated HB; PHNET, primary hepatic neuroendocrine tumor; NET, neuroendocrine tumor; NEC, neuroendocrine carcinoma; MiNEN, mixed neuroendocrine-non-neuroendocrine neoplasm.

\section{Acknowledgments}

Thanks to our students for helping us to search the literature for a long time. This study was supported by the Scientific Research Project of Beijing You-an Hospital, CCMU (YNKTTS20180110), You-an Foundation of Liver Disease and AIDS (YNKTTS20180123) and Beijing Fengtai Health System Research Project (2018-63).

\section{Author Contributions}

All authors contributed to data analysis, drafting or revising the article, gave final approval of the version to be published, agreed to the submitted journal, and agree to be accountable for all aspects of the work.

\section{Disclosure}

There is no potential conflict of interest involved in this paper. 


\section{References}

1. Doherty MR, Cheon H, Junk DJ, et al. Interferon-beta represses cancer stem cell properties in triple-negative breast cancer. Proc Natl Acad Sci U S A. 2017;114(52):13792-13797. doi:10.1073/ pnas. 1713728114

2. Hu Z, Artibani M, Alsaadi A, et al. The repertoire of serous ovarian cancer non-genetic heterogeneity revealed by single-cell sequencing of normal fallopian tube epithelial cells. Cancer Cell. 2020;37(2):226-242. doi:10.1016/j.ccell.2020.01.003

3. Wu HJ, Chu PY. Role of Cancer stem cells in cholangiocarcinoma and therapeutic implications. Int J Mol Sci. 2019;20(17):4154. doi:10.3390/ijms20174154

4. Nagtegaal ID, Odze RD, Klimstra D, et al. WHO Classification of Tumours of the Digestive System. 5th ed. Lyon: International Agency for Research on Cancer; 2019:216-217.

5. Hu AB, He XS, Cai JY, Zheng QC, Lei TN, Guo ZG. Hepatic differentiation of mouse ES cells into BE cells in vitro. Cell Biol Int. 2006;30(5):459-465. doi:10.1016/j.cellbi.2006.01.006

6. Terada T. Human ductal plate and its derivatives express antigens of cholangiocellular, hepatocellular, hepatic stellate/progenitor cell, stem cell, and neuroendocrine lineages, and proliferative antigens. Exp Biol Med. 2017;242:907-917.

7. Haruna Y, Saito K, Spaulding S, Nalesnik MA, Gerber MA. Identification of bipotential progenitor cells in human liver development. Hepatology. 1996;23(3):476-481. doi:10.1002/ hep. 510230312

8. Strick-Marchand H, Weiss MC. Embryonic liver cells and permanent lines as models for hepatocyte and bile duct cell differentiation. Mech Dev. 2003;120(1):89-98. doi:10.1016/ S0925-4773(02)00335-0

9. Behbahan IS, Duan Y, Lam A, et al. New approaches in the differentiation of human embryonic stem cells and induced pluripotent stem cells toward hepatocytes. Stem Cell Rev. 2011;7 (3):748-759. doi:10.1007/s12015-010-9216-4

10. Schmelzer E, Zhang L, Bruce A, et al. Human hepatic stem cells from fetal and postnatal donors. J Exp Med. 2007;204 (8):1973-1987. doi:10.1084/jem.20061603

11. Dan YY, Riehle KJ, Lazaro C, et al. Isolation of multipotent progenitor cells from human fetal liver capable of differentiating into liver and mesenchymal lineages. Proc Natl Acad Sci U S A. 2006;103(26):9912-9917. doi:10.1073/pnas.0603824103

12. $\mathrm{Xu} \mathrm{J}, \mathrm{Hu} \mathrm{Y}$, Wang J, Zhou J, Zhang $\mathrm{T}$, Yu $\mathrm{H}$. Immunohistochemical characterization of hepatic stem cell-related cells in developing human liver. Front Med China. 2007;1(3):264-268. doi:10.1007/s11684-007-0050-2

13. Iglesias BV, Centeno G, Pascuccelli H, et al. Expression pattern of glypican-3 (GPC3) during human embryonic and fetal development. HistolHistopathol. 2008;23(11):1333-1340.

14. Herrera MB, Bruno S, Buttiglieri S, et al. Isolation and characterization of a stem cell population from adult human liver. Stem Cells. 2006;24:2840-2850. doi:10.1634/stemcells.2006-0114

15. Lemaigre FP. Development of the biliary tract. Mech Dev. 2003;120(1):81-87. doi:10.1016/S0925-4773(02)00334-9

16. Vestentoft PS, Jelnes P, Hopkinson BM, et al. Three-dimensional reconstructions of intrahepatic bile duct tubulogenesis in human liver. BMC Dev Biol. 2011;11(56). doi:10.1186/1471-213X-11-56

17. Roskams T, Desmet V. Embryology of extra- and intrahepatic bile ducts, the ductal plate. Anat Rec. 2008;291(6):628-635. doi:10.1002/ar.20710

18. Desmet VJ, Van Eyken P, Sciot R. Cytokeratins for probing cell lineage relationships in developing liver. Hepatology. 1990;12 (5):1249-1251. doi:10.1002/hep.1840120530

19. Shah KD, Gerber MA. Development of intrahepatic bile ducts in humans. Immunohistochemical study using monoclonal cytokeratin antibodies. Arch Pathol Lab Med. 1989;113(10):1135-1138.
20. Lombard CA, Prigent J, Sokal EM. Human liver progenitor cells for liver repair. Cell Med. 2013;5(1):1-16. doi:10.3727/ 215517913 X666459

21. Carpino G, Renzi A, Franchitto A, et al. Stem/progenitor cell niches involved in hepatic and biliary regeneration. Stem Cells Int. 2016;2016:3658013. doi:10.1155/2016/3658013

22. Terada T. Development of extrahepatic bile duct excluding gall bladder in human fetuses: histological, histochemical, and immunohistochemical analysis. Microsc Res Tech. 2014;77 (10):832-840. doi:10.1002/jemt.22406

23. Overi D, Carpino G, Cardinale V, et al. Contribution of resident stem cells to liver and biliary tree regeneration in human diseases. Int J Mol Sci. 2018;19:2917. doi:10.3390/ijms19102917

24. Roskams T, Cassiman D, De Vos R, Libbrecht L. Neuroregulation of the neuroendocrine compartment of the liver. Anat Rec a DiscovMol Cell Evol Biol. 2004;280(1):910-923. doi:10.1002/ ar.a.20096

25. Kanda N, Fukuda Y, Imoto M, Koyama Y, Nakano I, Urano F. Localization of synaptophysin immunoreactivity in the human liver. Scand J Gastroenterol. 1994;29(3):275-279. doi:10.3109/ 00365529409090476

26. Grozdanov PN, Yovchev MI, Dabeva MD. The oncofetal protein glypican-3 is a novel marker of hepatic progenitor/oval cells. $L a b$ Invest. 2006;86(12):1272-1284. doi:10.1038/labinvest.3700479

27. Darwiche H, Petersen BE. Biology of the adult hepatic progenitor cell: "Ghosts in the machine.". Prog Mol Biol Transl Sci. 2010;97:229-249.

28. Chaudhari P, Tian L, Deshmukh A, Jang -Y-Y. Expression kinetics of hepatic progenitor markers in cellular models of human liver development recapitulating hepatocyte and biliary cell fate commitment. Exp Biol Med. 2016;241(15):1653-1662. doi:10.1177/1535370216657901

29. Katoonizadeh A, Poustchi H. Adult hepatic progenitor cell niche: how it affects the progenitor cell fate. Middle East J Dig Dis. 2014;6(2):57-64.

30. Carpino G, Cardinale V, Onori P, et al. Biliary tree stem/progenitor cells in glands of extrahepatic and intraheptic bile ducts: an anatomical in situ study yielding evidence of maturational lineages. $J$ Anat. 2012;220(2):186-199. doi:10.1111/j.14697580.2011.01462.x

31. Alvaro D, Gaudio E. Biliary tree stem cell subpopulations. Hepatology. 2016;64:644. doi:10.1002/hep.28546

32. Tomita H, Kanayama T, Niwa A, et al. Chapter 13 - the stem cells in liver cancers and the controversies. In: Zheng Y-W, editor. Stem Cells and Cancer in Hepatology. Academic Press; 2018:273-287.

33. Nishikawa Y, Doi Y, Watanabe H, et al. Transdifferentiation of mature rat hepatocytes into bile duct-like cells in vitro. $\mathrm{Am}$ $J$ Pathol. 2005;166(4):1077-1088. doi:10.1016/S0002-9440(10) 62328-0

34. Doffou M, Adams G, Bowen WC, et al. Oct4 is crucial for transdifferentiation of hepatocytes to biliary epithelial cells in an in vitro organoid culture model. Gene Expr. 2018;18(1):51-62. doi:10.3727/105221617X15124876321401

35. Zhu C, Dong B, Sun L, Wang Y, Chen S. Cell sources and influencing factors of liver regeneration: a review. Med Sci Monit. 2020;26:e929129. doi:10.12659/MSM.929129

36. Font-Burgada J, Shalapour S, Ramaswamy S, et al. Hybrid periportal hepatocytes regenerate the injured liver without giving rise to cancer. Cell. 2015;162(4):766-779. doi:10.1016/j.cell.2015.07.026

37. Banga A, Akinci E, Lucas V, et al. In vivo reprogramming of Sox9+ cells in the liver to insulin-secreting ducts. Proc Nat Acad Sci. 2012;109(38):15336-15341. doi:10.1073/pnas.1201701109

38. Tarlow BD, Pelz C, Naugler WE, et al. Bipotential adult liver progenitors are derived from chronically injured mature hepatocytes. Cell Stem Cell. 2014;15(5):605-618. doi:10.1016/j. stem.2014.09.008 
39. Segal JM, Kent D, Wesche DJ, et al. Single cell analysis of human foetal liver captures the transcriptional profile of hepatobiliary hybrid progenitors. Nat Commun. 2019;10(1):3350. doi:10.1038/s41467-019-11266-x

40. Zabulica M, Jakobsson T, Ravaioli F, et al. Gene editing correction of a urea cycle defect in organoid stem cell derived hepatocyte-like cells. Int J Mol Sci. 2021;22(3):1217. doi:10.3390/ijms22031217

41. Zabulica M, Srinivasan RC, Vosough M, et al. Guide to the assessment of mature liver gene expression in stem cell-derived hepatocytes. Stem Cells Dev. 2019;28(14):907-919. doi:10.1089/ scd.2019.0064

42. Lin Y, Fang ZP, Liu HJ, et al. HGF/R-spondin1 rescues liver dysfunction through the induction of Lgr5+ liver stem cells. Nat Commun. 2017;8(1):1175. doi:10.1038/s41467-017-01341-6

43. Sekiya S, Suzuki A. Hepatocytes, rather than cholangiocytes, can be the major source of primitive ductules in the chronically injured mouse liver. Am J Pathol. 2014;184(5):1468-1478. doi:10.1016/j.ajpath.2014.01.005

44. Schmelzer E, Wauthier E, Reid LM. The phenotypes of pluripotent human hepatic progenitors. Stem Cells. 2006;24:1852-1858. doi:10.1634/stemcells.2006-0036

45. Chao J, Zhao S, Sun H. Dedifferentiation of hepatocellular carcinoma: molecular mechanisms and therapeutic implications. $\mathrm{Am}$ J Transl Res. 2020;12(5):2099-2109.

46. Scesa G, Adami R, Bottai D. iPSC preparation and epigenetic memory: does the tissue origin matter? Cells. 2021;10(6):1470. doi: $10.3390 /$ cells 10061470

47. Libbrecht L, De Vos R, Cassiman D, Desmet V, Aerts R, Roskams T. Hepatic progenitor cells in hepatocellular adenomas. Am J Surg Pathol. 2001;25(11):1388-1396. doi:10.1097/00000478-200111000-00006

48. Iyer A, Robert ME, Bifulco CB, Salem RR, Jain D. Different cytokeratin and neuronal cell adhesion molecule staining patterns in focal nodular hyperplasia and hepatic adenoma and their significance. Hum Pathol. 2008;39(9):1370-1377. doi:10.1016/j. humpath.2008.01.015

49. Schotanus BA, Kruitwagen HS, van den Ingh TS, et al. Enhanced Wnt/ $\beta$-catenin and Notch signalling in the activated canine hepatic progenitor cell niche. BMC Vet Res. 2014;10:309. doi:10.1186/ s12917-014-0309-1

50. Micsenyi A, Tan X, Sneddon T, Luo JH, Michalopoulos GK, Monga SP. Beta-catenin is temporally regulated during normal liver development. Gastroenterology. 2004;126:1134-1146. doi:10.1053/j.gastro.2003.12.047

51. Sempoux C, Balabaud C, Bioulac-Sage P. Pictures of focal nodular hyperplasia and hepatocellular adenomas. World $J$ Hepatol. 2014;6:580-595. doi:10.4254/wjh.v6.i8.580

52. Walther Z, Jain D. Molecular pathology of hepatic neoplasms: classification and clinical significance. Patholog Res Int 2011;2011:403929. doi:10.4061/2011/403929

53. Fonseca S, Hoton D, Dardenne S, et al. Histological and immunohistochemical revision of hepatocellular adenomas: a learning experience. Int $J$ Hepatol. 2013;2013:398308. doi:10.1155/2013/ 398308

54. Matthai SM, Ramakrishna B. Cancer stem cells in hepatocellular carcinoma - an immunohistochemical study with histopathological association. Indian $J$ Med Res. 2015;142(4):391-398. doi:10.4103/0971-5916.169195

55. Xiang Y, Yang T, Pang B, Zhu Y, Liu Y. The progress and prospects of putative biomarkers for liver cancer stem cells in hepatocellular carcinoma. Stem Cells Int. 2016;2016:7614971. doi:10.1155/2016/7614971

56. Berretta M, Cavaliere C, Alessandrini L, et al. Serum and tissue markers in hepatocellular carcinoma and cholangiocarcinoma: clinical and prognostic implications. Oncotarget. 2017;8 (8):14192-14220. doi:10.18632/oncotarget.13929
57. Ben-Porath I, Thomson MW, Carey VJ, et al. An embryonic stem cell-like gene expression signature in poorly differentiated aggressive human tumors. Nat Genet. 2008;40:499-507. doi:10.1038/ng.127

58. Feng J, Zhu R, Feng D, et al. Prediction of early recurrence of solitary hepatocellular carcinoma after orthotopic liver transplantation. Sci Rep. 2019;9:15855. doi:10.1038/s41598-01952427-8

59. Fujii T, Zen Y, Harada K, et al. Participation of liver cancer stem/ progenitor cells in tumorigenesis of scirrhous hepatocellular carcinoma-human and cell culture study. Hum Pathol. 2008;39:1185-1196. doi:10.1016/j.humpath.2007.12.010

60. Van Eyken P, Sciot R, Brock P, Casteels-van Daele M, Ramaekers FC, Desmet VJ. Abundant expression of cytokeratin 7 in fibrolamellar carcinoma of the liver. Histopathology. 1990;17:101-107. doi:10.1111/j.1365-2559.1990.tb00679.x

61. Feng J, Zhu R, Chang C, et al. CK19 and glypican 3 expression profiling in the prognostic indication for patients with HCC after surgical resection. PLoS One. 2016;11(3):e0151501. doi:10.1371/ journal.pone. 0151501

62. Feng J, Chen J, Zhu R, et al. Prediction of early recurrence of hepatocellular carcinoma within the Milan criteria after radical resection. Oncotarget. 2017;8(38):63299-63310. doi:10.18632/ oncotarget.18799

63. Kim H, Park C, Han KH, et al. Primary liver carcinoma of intermediate (hepatocyte-cholangiocyte) phenotype. $J$ Hepatol. 2004;40:298-304. doi:10.1016/j.jhep.2003.10.023

64. Ding SJ, Li Y, Tan YX, et al. From proteomic analysis to clinical significance: overexpression of cytokeratin 19 correlates with hepatocellular carcinoma metastasis. Mol Cell Proteomics. 2004;3:73-81. doi:10.1074/mcp.M300094-MCP200

65. Lee KB. Histopathology of a benign bile duct lesion in the liver: morphologic mimicker or precursor of intrahepatic cholangiocarcinoma. Clin Mol Hepatol. 2016;22(3):400-405. doi: $10.3350 / \mathrm{cmh} .2016 .0105$

66. Bell D, Ranganathan S, Tao J, Monga SPS. Novel advances in understanding of molecular pathogenesis of hepatoblastoma: a Wnt/ $\beta$-catenin perspective. Gene Expr. 2017;17(2):141-154. doi:10.3727/105221616X693639

67. Tsuchida Y, Ikeda H, Suzuki N, et al. A case of well-differentiated, fetal-type hepatoblastoma with very low serum alpha-fetoprotein. $J$ Pediatr Surg. 1999;34 (12):1762-1764. doi:10.1016/S0022-3468(99)90307-X

68. Lee CT, Zhang L, Mounajjed T, Wu TT. High mobility group AT-hook 2 is overexpressed in hepatoblastoma. Hum Pathol. 2013;44(5):802-810. doi:10.1016/j.humpath.2012.08.003

69. Haas JE, Muczynski KA, Krailo M, et al. Histopathology and prognosis in childhood hepatoblastoma and hepatocarcinoma. Cancer. 1989;64(5):1082-1095. doi:10.1002/1097-0142(19890901)64:5<1082::AID-CNCR2820640520>3.0.CO;2-G

70. Zimmermann A. Variants of the hepatoblastoma tumor family. In: Tumors and Tumor-Like Lesions of the Hepatobiliary Tract. Cham: Springer; 2017. doi:10.1007/978-3-319-26956-6_20

71. Ruck P, Xiao JC, Kaiserling E. Small epithelial cells and the histogenesis of hepatoblastoma.Electron microscopic, immunoelectron microscopic, and immunohistochemical findings. $\mathrm{Am}$ J Pathol. 1996;148(1):321-329.

72. Cairo S, Armengol C, De Reyniès A, et al. Hepatic stem-like phenotype and interplay of $\mathrm{Wnt} / \beta$-catenin and myc signaling in aggressive childhood liver cancer. Cancer Cell. 2008;14 (6):471-484. doi:10.1016/j.ccr.2008.11.002

73. Alisi A, Cho WC, Locatelli F, Fruci D. Multidrug resistance and cancer stem cells in neuroblastoma and hepatoblastoma. Int $\mathrm{J} \mathrm{Mol}$ Sci. 2013;14(12):24706-24725. doi:10.3390/ijms141224706

74. Zhang C, Liu Y, Wang Q, Chen H. Clinicopathological analysis of hepatoblastoma. J Clin Pediatr. 2015;33(10):912-913. 
75. Van Eyken P, Sciot R, Callea F, Ramaekers F, Schaart G, Desmet VJ. A cytokeratin-immunohistochemical study of hepatoblastoma. Hum Pathol. 1990;21(3):302-308. doi:10.1016/ 0046-8177(90)90231-S

76. Chattopadhyay S, Mukherjee S, Boler A, Sharma A, Biswas SK. Hepatoblastoma in the neonatal period: an unusual presentation. J Cytol. 2012;29(4):252-254. doi:10.4103/0970-9371.103945

77. Tanaka $\mathrm{Y}$, Inoue $\mathrm{T}$, Horie $\mathrm{H}$. International pediatric liver cancer pathological classification: current trend. Int $J$ Clin Oncol. 2013;18:946-954. doi:10.1007/s10147-013-0624-8

78. López-Terrada D, Alaggio R, de Dávila MT, et al. Towards an international pediatric liver tumor consensus classification: proceedings of the Los Angeles COG liver tumors symposium. Mod Pathol. 2014;27(3):472-491. doi:10.1038/modpathol.2013.80

79. Von Schweinitz D, Leuschner I, Glüer S, Pietsch T. Expression of cell adhesion molecules and common acute lymphoblastic leukaemia antigen in hepatoblastoma. Virchows Arch. 1996;429(45):235-241. doi:10.1007/BF00198339

80. Quartey B. Primary hepatic neuroendocrine tumor: what do we know now? World J Oncol. 2011;2(5):209-216. doi:10.4021/ wjon341w

81. Kim JM, Kim SY, Kwon CHD, et al. Primary hepatic neuroendocrine carcinoma. Korean J Hepatobiliary Pancreat Surg. 2013;17 (1):34-37. doi:10.14701/kjhbps.2013.17.1.34

82. Yang K, Cheng Y-S, Yang -J-J, Jiang X, Guo J-X. Primary hepatic neuroendocrine tumors: multi-modal imaging features with pathological correlations. Cancer Imaging. 2017;17:20. doi:10.1186/ s40644-017-0120-x

83. Jo JM, Cho YK, Hyun CL, et al. Small cell carcinoma of the liver and biliary tract without jaundice. World J Gastroenterol. 2013;19 (44):8146-8150. doi:10.3748/wjg.v19.i44.8146

84. Torbenson M. Fibrolamellar carcinoma: 2012 update. Scientifica. 2012;2012:743-790.

85. Krings G, Ramachandran R, Jain D, et al. Immunohistochemical pitfalls and the importance of glypican 3 and arginase in the diagnosis of scirrhous hepatocellular carcinoma. Mod Pathol. 2013;26:782-791. doi:10.1038/modpathol.2012.243

86. Fragulidis GP, Chondrogiannis K, Vezakis A, et al. Neuroendocrine differentiation in embryonal type hepatoblastoma. Hepatol Res. 2013;43(3):320. doi:10.1111/ j.1872-034X.2012.01070.x

87. He C, Yin HF, Liu P, et al. Clinicopathologic features of combined hepatic carcinoma. Chin j Pathol. 2013;42(12):824.

88. Zhao M, Laissue JA, Zimmermann A. 'Neuroendocrine' differentiation in hepatocellular carcinomas (HCCs): immunohistochemical reactivity is related to distinct tumor cell types, but not to tumor grade. Histol Histopathol. 1993;8(4):617-626.

89. DeSano JT, Xu L. MicroRNA regulation of cancer stem cells and therapeutic implications. AAPS J. 2009;11(4):682-692. doi:10.1208/s12248-009-9147-7

90. Matsui WH. Cancer stem cell signaling pathways. Medicine. 2016;95(1 Suppl 1):S8-S19. doi:10.1097/MD.000000000 0004765

91. Tarayrah L, Chen X. Epigenetic regulation in adult stem cells and cancers. Cell Biosci. 2013;3(1):41. doi:10.1186/2045-3701-3-41

92. Herrera SC, Bach EA. JAK/STAT signaling in stem cells and regeneration: from Drosophila to vertebrates. Development. 2019;146(2):dev167643. doi:10.1242/dev.167643

93. Varlakhanova NV, Cotterman RF, Devries WN, et al. Myc maintains embryonic stem cell pluripotency and self-renewal. Differentiation. 2010;80(1):9-19. doi:10.1016/j.diff.2010.05.001
94. Arsic N, Gadea G, Lagerqvist EL, et al. The p53 isoform $\Delta 133$ p53 $\beta$ promotes cancer stem cell potential. Stem Cell Rep. 2015;4(4):531-540. doi:10.1016/j.stemcr.2015.02.001

95. Chapman-Rothe N, Curry E, Zeller C, et al. Chromatin $\mathrm{H} 3 \mathrm{~K} 27 \mathrm{me} 3 / \mathrm{H} 3 \mathrm{~K} 4 \mathrm{me} 3$ histone marks define gene sets in high-grade serous ovarian cancer that distinguish malignant, tumour-sustaining and chemo-resistant ovarian tumour cells. Oncogene. 2013;19:4586-4592. doi:10.1038/onc.2012.477

96. Smith ZD, Shi J, Gu H, et al. Epigenetic restriction of extraembryonic lineages mirrors the somatic transition to cancer. Nature. 2017;549:543-547. doi:10.1038/nature23891

97. Bao S, Wu Q, Sathornsumetee S, et al. Stem cell-like glioma cells promote tumor angiogenesis through vascular endothelial growth factor. Cancer Res. 2006;15:7843-7848. doi:10.1158/0008-5472. CAN-06-1010

98. Utermöhlen O, Krönke M. Survival of priceless cells: active and passive protection of embryonic stem cells against immune destruction. Arch Biochem Biophys. 2007;462:273-277. doi:10.1016/j.abb.2007.03.032

99. Lin VTG, Pruitt HC, Samant RS, et al. Developing cures: targeting ontogenesis in cancer. Trends Cancer. 2017;3(2):126-136. doi:10.1016/j.trecan.2016.12.007

100. Duraiswamy J, Kaluza KM, Freeman GJ, et al. Dual blockade of PD-1 and CTLA-4 combined with tumor vaccine effectively restores T-cell rejection function in tumors. Cancer Res. 2013;73(12):3591-3603. doi:10.1158/0008-5472.CAN-12-4100

101. Hombach AA, Görgens A, Chmielewski M, et al. Superior therapeutic index in lymphoma therapy: CD30(+) CD34(+) hematopoietic stem cells resist a chimeric antigen receptor T-cell attack. Mol Ther. 2016;24(8):1423-1434. doi:10.1038/mt.2016.82

102. Stewart-Morgan KR, Petryk N, Groth A. Chromatin replication and epigenetic cell memory. Nat Cell Biol. 2020;22(4):361-371. doi:10.1038/s41556-020-0487-y

103. Zhang W, Feng J, Li Q. The replisome guides nucleosome assembly during DNA replication. Cell Biosci. 2020;10:37. doi:10.1186/s13578-020-00398-Z

104. Wooten M, Ranjan R, Chen X. Asymmetric histone inheritance in asymmetrically dividing stem cells. Trends Genet. 2020;36 (1):30-43. doi:10.1016/j.tig.2019.10.004

105. Reverón-Gómez N, González-Aguilera C, Stewart-Morgan KR, et al. Accurate recycling of parental histones reproduces the histone modification landscape during DNA replication. Mol Cell. 2018;72(2):239-249.e5. doi:10.1016/j.molcel.2018.08.010

106. Massa A, Varamo C, Vita F, et al. Evolution of the experimental models of cholangiocarcinoma. Cancers. 2020;12(8):2308. doi:10.3390/cancers 12082308

107. D'Avola D, Villacorta-Martin C, Martins-Filho SN, et al. Highdensity single cell mRNA sequencing to characterize circulating tumor cells in hepatocellular carcinoma. Sci Rep. 2018;8 (1):11570. doi:10.1038/s41598-018-30047-y

108. Zheng H, Pomyen Y, Hernandez MO, et al. Single-cell analysis reveals cancer stem cell heterogeneity in hepatocellular carcinoma. Hepatology. 2018;68(1):127-140. doi:10.1002/ hep. 29778

109. Ha K, Fujita M, Karlić R, et al. Somatic mutation landscape reveals differential variability of cell-of-origin for primary liver cancer. Heliyon. 2020;6(2):e03350. doi:10.1016/j.heliyon.2020. $\mathrm{e} 03350$ 


\section{Publish your work in this journal}

The Journal of Hepatocellular Carcinoma is an international, peerreviewed, open access journal that offers a platform for the dissemination and study of clinical, translational and basic research findings in this rapidly developing field. Development in areas including, bu not limited to, epidemiology, vaccination, hepatitis therapy, pathology and molecular tumor classification and prognostication are all considered for publication. The manuscript management system is completely online and includes a very quick and fair peer-review system, which is all easy to use. Visit http://www.dovepress.com/ testimonials.php to read real quotes from published authors.

Submit your manuscript here: https://www.dovepress.com/journal-of-hepatocellular-carcinoma-journal 